Author version: Geochim. Cosmochim. Acta, vol.131; 2014; 247-266

\title{
REFRACTORY METAL NUGGETS IN DIFFERENT TYPES OF COSMIC SPHERULES
}

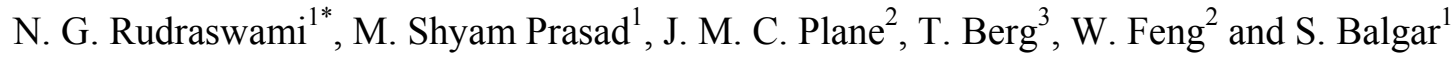 \\ ${ }^{1}$ National Institute of Oceanography (Council of Scientific and Industrial Research), Dona Paula, \\ Goa 403 004, India \\ ${ }^{2}$ School of Chemistry, University of Leeds, Leeds LS29JT, UK \\ ${ }^{3}$ Institut für Physik, Johannes Gutenberg-Universität, Staudingerweg 7, D-55128 Mainz, Germany \\ *Corresponding Author: rudra@nio.org
}

\begin{abstract}
Out of the three basic cosmic spherule types collected from the seafloor, RMNs (Refractory Metal Nuggets) have been reported from I-type spherules commonly, rarely from S-type spherules and never from the G-type spherules. Nuggets in the I-type cosmic spherules have formed by melting and complete oxidation during atmospheric entry, whereas no clear understanding emerged so far regarding the formation of the rare nuggets in S-type spherules. We collected cosmic spherules by raking the deep seafloor with magnets, and carried out systematic and sequential grinding, polishing and electron microscopic investigations on 992 cosmic spherules to identify RMNs. Fifty-four nuggets (RMNs) are identified, out of which 23, 26, and 5 nuggets are recovered from $23 \mathrm{I}-, 21 \mathrm{~S}-$ and $5 \mathrm{G}$-type cosmic spherules, respectively.

The nuggets in all the three spherule types follow a pattern indicative of their formation by metal segregation during atmospheric entry due to heating and oxidation, however, there are differences in their elemental distribution patterns. The refractory metal elements (RMEs) in the Itype spherules show a sequence of volatilization form a chondritic source, however, the relatively volatile RMEs in these spherules seem to be either depleted or distributed in numerous smaller nuggets. However, RMNs in the G-type spherules show closer conformity to CI chondrites and do not have a large volatile RME depletion. Whereas, the RMEs in the nuggets found in the S-type spherules are enriched in the volatile as well as the refractory elements. Also all the spherules show enrichment patterns and elemental ratios that are close to CI composition for refractory elements suggesting a common mechanism of formation. Pulse heating during atmospheric entry seems to be an efficient mechanism for RME segregation into nuggets. The patterns of RME enrichment and elemental ratios when compared with the nuggets in CAIs, show marked variations, outlining their differences in the process of formation. In addition, we also discovered a fremdling-like object in a cosmic spherule which has a nugget encased in Fe-Ni and sulfide phases, similar to those typically observed in CAIs of $\mathrm{CV}$ or $\mathrm{CO}$ chondrites. The atmospheric entry for this rare cosmic spherule appears to have taken place at a high zenith angle with a low entry velocity, so that its volatile phases are well preserved.
\end{abstract}




\section{INTRODUCTION}

Asteroidal collisions and cometary out-gassing produce micrometeorites which enter the Earth's upper atmosphere with a highly uncertain input, ranging from about 5 to $300 \mathrm{t} \mathrm{d}^{-1}$ (Plane, 2012; Cremonese et al., 2012). These particles during their atmospheric passage are heated and ablated depending on their mass, entry velocity and angle, leading to changes in their chemical and mineralogical composition and texture (Love and Brownlee, 1991; Vondrak et al., 2008). A large fraction (perhaps up to 90\%) of the meteoroids that enter the earth's atmosphere completely vaporize (Love and Brownlee, 1993; Taylor et al., 1998; Peucker-Ehrenbrink and Ravizza, 2000). Many of the remaining meteoroids, which survive entry and become micrometeorites fully or at least partially melt during entry into the earth's atmosphere, thereby losing their original texture and chemical compositions.

Heating of these particles during atmospheric entry can lead to melting and the formation of 'cosmic spherules' (Blanchard et al., 1980). Three basic types of cosmic spherules have been identified: the silicate or S-type, iron or I-type and the enigmatic glassy or G-type. Progressive heating and evaporation of $\mathrm{Fe}$ in the particles leads to different types of textures in the S-type spherules starting from the very porous scoriaceous to the highly refractory CAT (Ca-Al-Ti rich) spherules (Brownlee, 1997; Taylor et al. 2000; Genge et al., 2008). The I-type spherules comprise of a combination of magnetite and wustite and often contain an Fe-Ni bead (Blanchard et al., 1980). On occasion they can enclose refractory metal nuggets (RMNs) (Brownlee et al., 1984; Bonte et al., 1987; Rudraswami et al., 2011). Although their Fe-Ni bulk compositions suggest a metal-rich parent body, it has been observed that the majority of these spherules have originated from chondritic parent bodies, which have been heated during atmospheric entry leading to metal segregation and subsequent oxidation causing the formation of wustite and magnetite (Brownlee et. al., 1984; Genge and Grady, 1998). However, the finding of cosmogenic radionuclides in some I-type spherules suggests that not all of them originated in this fashion, some of the I-type spherules could be pristine bodies which entered the earth's atmosphere as Fe-Ni particles (Herzog et al., 1999).

The G-type spherules contain a dendritic network of magnetites in a glassy groundmass and often contain a Fe-Ni bead (Blanchard et al., 1980). Their origin has so far remained enigmatic. They have been suggested to be the end products of vapour fractionation from metal-rich stony meteorites (Blanchard et al., 1980); an enstatite chondrite (Bates, 1986); a totally different metal-rich asteroid 
(Brownlee et al. 1997); or, in view of their silicate-metal combination and chromite content, derived from stony-iron type meteorites (Robin et al., 1988).

Extreme heating and oxidation leads to the segregation of refractory metal elements (RMEs) in Itype spherules in the form of nuggets, whose chemical compositions show a volatilization sequence from a chondritic source (Brownlee et al., 1984; Rudraswami et al., 2011). Such nuggets have been observed only in I-type spherules. The only exceptions have been the finding of RMNs in two Stype spherules: barred (Bonte et al., 1987) and more recently in a glass cosmic spherule (Rudraswami et al., 2012). In both these spherules, the Pt-group composition is not compatible with the known chondritic ratios. Refractory metal nuggets have been found commonly in calcium aluminium rich inclusions (CAIs) (Brearly and Jones, 1998; Campbell et al., 2003), in a few chondrules and the matrix of a CV3 carbonaceous chondrite (Hua et al., 2005), and have been consistently suggested to be among the earliest formed solar system materials (Hutcheon et al., 1987). Most of the nuggets in carbonaceous chondrites do not have chondritic ratios. Several reasons have been put forward to explain these compositions are sulfidation, exsolution, and oxidation in early solar nebula environments (Campbell et al., 2003 and references therein).

The bulk chemistry of most cosmic spherules is related to carbonaceous chondrites (Kurat et al., 1994; Beckerling and Bischoff, 1995; Brownlee et al., 1997; Greshake et al., 1998; Engrand et al., 1999), and thousands of spherules studied so far have not given an unambiguous link to either CAIs or chondrules, in spite of chondrules being ubiquitous in all chondritic meteorites, where they constitute up to $\sim 70 \%$ by volume (Brearly and Jones, 1998). In contrast, CAIs are present largely in carbonaceous chondrites, they have modal abundances varying up to $\sim 3$ area\% (Hezel et al., 2008). While $90 \%$ of micrometeorites studied on the earth have a carbonaceous chondritic provenance, there have been few reports of the presence of CAIs among micrometeorites. The CAIs contain RME (W, Mo, Os, Ir, Ru, Rh, Pt, Pd) enriched nuggets, the enrichments of these nuggets is based on their condensation temperatures.

Cosmic spherules for the present study are collected from the sediments of the Indian Ocean by fixing magnets to a dredge which was dragged along the seafloor. Close to 1000 spherules of all the three basic types were sequentially ground and polished from this magnetically biased material for investigating RMNs. We analyzed nuggets founds in all the spherules for the elements $\mathrm{W}, \mathrm{Mo}$, Os, Ir, $\mathrm{Ru}, \mathrm{Rh}, \mathrm{Pt}, \mathrm{Pd}$ (in addition to $\mathrm{Fe}$ and $\mathrm{Ni}$ ) to understand the process of nugget formation in cosmic spherules. 


\section{SAMPLE PREPARATION AND ELECTRON MICROSCOPY}

The cosmic spherules were collected during the $26^{\text {th }}$ cruise of the AA Sidorenko (AAS-26), where a magnetic panel comprising of 6 bar magnets was fixed to a dredge and dragged along the deep sea floor of the Indian Ocean. Forty five operations were carried out during this 35-day cruise, the samples were brought back and after processing in the laboratory, the spherules were handpicked under a binocular microscope, mounted in epoxy and polished. For the present investigation, 992 spherules of diameters $\geq 150 \mu \mathrm{m}$, mounted on 26 epoxy mounts, were systematically polished to a depth of $\sim 5-10 \mu \mathrm{m}$, followed by scanning electron microscope (SEM) analysis to identify the presence of RMNs within the spherules. This approach is similar to that used by Brownlee et al. (1984). Each mount was ground and polished $~ 7-10$ times in this manner and was observed in the SEM after each grinding/polishing cycle for identifying the presence of RMNs in the exposed portions of the spherules. This process was repeated till the spherules started getting plucked from the mounts.

A JEOL JSM 5800LV SEM attached with an OXFORD-INCA energy dispersive spectrometer detector (EDS, ISIS-300) system ( at the National Institute of Oceanography, Goa) was used for electron imaging and chemical analysis. An electron beam energy of $20 \mathrm{keV}$ was used for the EDS measurements. In order to improve the counting statistics the integration time per analysis was increased to $\sim 180$ seconds. High resolution back-scattered electron (BSE) images with varying magnification were inspected thoroughly to identify the presence of RMNs. Once a RMN was identified, the energy dispersive X-ray analyzer attached to the SEM was used to further probe its elemental composition. Pure platinum group element (PGE) standards $(99.9 \%)$ and the INCA program were used to provide the reference and XPP corrections, respectively. An Electron Micro Probe Analyzer (EPMA, Cameca SX-5 at National Institute of Oceanography, Goa) was used for obtaining bulk chemical composition. The parameters used for EPMA were: acceleration voltage $\sim 15 \mathrm{kV}$, a beam current $\sim 12 \mathrm{nA}$ and beam diameter $\sim 2 \mu \mathrm{m}$.

\section{RESULTS}

Of the 49 spherules that display RMNs, 23 spherules are of I-type, 21 of S-type and 5 of Gtype. The example of the nugget appearance has been shown in Fig. 1-5. In most cases, only one nugget per spherule was found; however, three barred olivine spherules contained multiple nuggets, the maximum being in D-P34 which contained four nuggets. Table 1 provides statistical details of the spherules containing refractory nuggets. In total, $\sim 5 \%$ of the observed spherules contain nuggets. 
It should be borne in mind that some of the nuggets may have been lost during the polishing. Furthermore, spherules are often plucked out of the epoxy once more than half of their volume has been removed by polishing.

\subsection{Nuggets in I-type spherules}

Spherules of diameter $\geq 150 \mu \mathrm{m}$ were chosen for this study, out of which the I-type spherules have a diameter range of $\sim 150-300 \mu \mathrm{m}$ (Fig. 1-2). Out of 992 cosmic spherules observed 292 are of I-type, and 23 of these spherules contain 23 micrometer sized nuggets. However, several spherules were also studied for nanometer sized nugget (Fig. 6). Prior to polishing, several large sized I-type spherules were examined in the SEM in order to assess the presence of RMNs adhering to their outer surfaces. This resulted in finding two nuggets on the surfaces of the spherules (Fig. 2). The relation that the size of nugget increases as the size of the spherule increases hold true, which in turn supports a segregation mechanism during atmospheric entry (Rudraswami et al., 2011).

The nugget-bearing spherules are mostly composed of magnetite with very little wustite (Fig. 1a), indicating that the spherules have undergone extreme oxidation during entry. The nuggets in the I-type spherules are generally spherical, however, in one spherule (D-P218) we found a spherical nugget to which an irregular-shaped small nugget is attached (Fig. 1f). The elongated nugget with the dimensions $\sim 2.5 \times 1 \mu \mathrm{m}$ is attached to a large nugget of size $\sim 5.5 \mu \mathrm{m}$. The irregular-shaped nugget had a depletion in PGE content when compared with the main nugget (Table 2).

RMNs observed in the CAIs of carbonaceous chondrites had the refractory siderophile elements Mo and W associated invariably with the PGEs which were found to be enriched several thousand times the CI average (Palme and Wlotzka, 1976; Wark and Lovering, 1976). The refractory elements $\mathrm{W}$ and Mo condense from the solar nebula in a common alloy along with the PGE in view of their similar condensation temperatures (Palme et al., 1994), the large presence of which distinguishes them from terrestrially occurring noble metal alloys (Harries et al., 2012). We, therefore analyzed the nuggets for the refractory metal elements (RMEs) W, Mo, Os, Ir, Ru, Rh, Pt, $\mathrm{Pd}$, (in addition to $\mathrm{Fe}$ and $\mathrm{Ni}$ ) in all the spherules.

The analytical data on the micrometer-sized nuggets observed in the I-type spherules is presented in Table 2. The I-type spherules basically exhibit two types of nuggets: the larger micrometer-sized $(>1 \mu \mathrm{m})$ and the smaller nanometer-sized ones (Figs. 1-2 and 6). The micrometer-sized nuggets are enriched in the refractory PGE (Ir, Os, Ru), and depleted in the volatile PGE (Pt, Rh, Pd) as can be 
seen in Fig. 7a. There is also a depletion of $\mathrm{W}$ in all the nuggets in addition to the strong depletion of Mo. Whereas, the nanometer sized nuggets are enriched in $\mathrm{Pt}, \mathrm{Rh}$ and sometimes $\mathrm{Pd}$ as well in addition to $\mathrm{Fe}$ and $\mathrm{Ni}$ (Table 3). This suggests the selective uptake of $\mathrm{Pt}$ and $\mathrm{Rh}$ by Fe-Ni because the condensation temperatures of these two PGEs are closest to Fe-Ni. Therefore Pt and $\mathrm{Rh}$ are observed to be the first PGEs to be segregated to form discrete nanometer-sized nuggets, the rest of the PGEs with increased heating and oxidation formed into a single nugget which is generally enriched in the refractory PGE (Ir, Os, Ru), and depleted in the volatile PGE (Pt, Rh, Pd) (Rudraswami et al. 2011). The micrometer-sized nuggets are generally found one per spherule. The nanometer-sized nuggets are found in large numbers throughout the I-type spherules (Fig. 6).

Palme et al. (1994) observed during heating and oxidation W and Mo tend to oxidize, and W was found to migrate into the surrounding silicates as oxide thus showing a $\mathrm{W}$ depletion in the samples. The CI normalized elemental ratios (Tagle and Berlin, 2008) of the micrometer-sized nuggets in I-type spherules show a close agreement with CI ratios with respect to the more refractory elements (Os/Ir and Ru/Ir) but show a strong deviation with respect to the more volatile PGE such as the Pt, Rh and Pd systematics (Fig. 8a). This indicates a volatility related pattern from an original CI chondritic composition similar to the one suggested by Brownlee et al. (1984). The Ir versus Os and $\mathrm{Pt}$ versus $\mathrm{Rh}$ show positive correlation, while the $\mathrm{Pt}$ and $\mathrm{Ru}$ versus Os show negative correlation (Fig. 9).

The presence of nanometer nuggets in I-type spherules is unique only to these spherule types, such nuggets have not been observed in the G- and the S-type spherules. They are found dominantly in the magnetite portions of the I-type spherules and are observed in large numbers (Fig. 6). The chemical compositions of I-type spherules that host the nuggets have FeO contents $\sim 90-99 \mathrm{wt} \%$ and $\mathrm{NiO} \sim 1-10 \mathrm{wt} \%$, with many spherules having small amounts of $\mathrm{Cr}$ (Appendix I). The NiO contents are closer to $1-2 \%$ in the majority of the spherules, the low Ni contents suggest that these spherules have undergone large scale oxidation. Only one of the I-type spherules (D-P125) has a nugget in the wustite phase, this spherule has relatively minor amounts of magnetite (Fig. 1b). Also D-P43 has a nugget close to center of the spherule which is not commonly observed in I-type spherules. This nugget has a high Pd percentage $(\sim 3.2 \%)$, along with D2-P10 nugget that has a higher Pd content of $\sim 7 \%$ (Table 2). The entire process of the isolation of Fe-Ni beads which upon heating and oxidation leading to the formation of nanometer-sized nuggets rich in $\mathrm{Pt}$ and $\mathrm{Rh}$ and formation of micrometersized nuggets enriched in Os and Ir has been suggested to occur within few seconds during atmospheric entry (Brownlee et al., 1984). 


\subsection{Nuggets in G-type spherules}

G-type spherules are usually identified by their textures that have magnetite dendrites and interstitial silicate glasses, some of them containing a Fe-Ni bead as well. Their chemical compositions show a dominance of Fe followed by $\mathrm{Ni}$, however they invariably contain appreciable percentages of $\mathrm{Mg}, \mathrm{Si}, \mathrm{Al}, \mathrm{Ca}$ etc.(Appendix I). Out of the observed spherules, 57 are of the G-type. A textural (and complementary chemical) variation is observed in the G-type spherules. Some of them have large Fe-Ni beads which also contain $\mathrm{Co}$, and a web of dendritic magnetites with interstitial silicate glass. The bead is missing in a few spherules, when the width of the dendrites is also seen to increase. Eventually, the dendritic magnetites assume even greater width and the glassy portion is reduced drastically, thereby making the spherule difficult to distinguish from the I-type; and the lithophile contents are observed to decrease in the spherules of this description. Nuggets are invariably observed in spherules of this description with the least amounts of interstitial glass (Fig. 3). This also implies progressive heating and oxidation leading to the segregation of the RME into nuggets by a mechanism which is similar to the one suggested for nugget formation in I-type spherules (Brownlee et al., 1984).

Five spherules contain nuggets with sizes ranging from $\sim 1.5$ to $7.2 \mu \mathrm{m}$ (Table 2). D-P28 has a large nugget with a diameter of $\sim 7.2 \mu \mathrm{m}$, nuggets of this size are usually found only in I-type spherules (Fig. 3a). The nugget is dominated by Os ( 18.6 wt\%), Ir ( 17.7 wt\%), Ru ( 20.9 wt\%) and $\operatorname{Pt}(\sim 29.1 \mathrm{wt} \%)$, with small percentages of $\mathrm{Rh}(\sim 3.7 \mathrm{wt} \%), \mathrm{Pd}(\sim 0.5 \mathrm{wt} \%), \mathrm{W}(\sim 0.7 \mathrm{wt} \%)$ and Mo $(\sim 0.4 \mathrm{wt} \%)$. A similarly large nugget (diameter $\sim 5.1 \mu \mathrm{m})$ was found in D4-126, which has minor amounts of Pd, W and Mo (Table 2). D-P14-II and D-P-123 have 3.1 and $2.6 \mu \mathrm{m}$ sized nuggets. D-P14-II has an abnormally high concentration of $\mathrm{Al}_{2} \mathrm{O}_{3}(\sim 17 \mathrm{wt} \%)$. The D-P365 nugget (diameter $\sim 1.5 \mu \mathrm{m}$ ) has a high concentration of $\mathrm{W}(\sim 11.7 \mathrm{wt} \%)$ and minor amounts of Mo. The bulk chemical composition of this spherule is enriched in $\mathrm{MgO}(\sim 19 \mathrm{wt} \%), \mathrm{SiO}_{2}(\sim 42 \mathrm{wt} \%)$ and $\mathrm{FeO}(\sim 34$ $\mathrm{wt} \%$ ). For the present study, the bulk chemical composition of $\mathrm{SiO}_{2}$ varies from $\sim 1$ to $42 \mathrm{wt} \%, \mathrm{MgO}$ from $\sim 2$ to $19 \mathrm{wt} \%$, and $\mathrm{Al}_{2} \mathrm{O}_{3}$ from $\sim 1$ to $18 \mathrm{wt} \%$ (Appendix I). The $\mathrm{FeO}$ contents of the spherules range from $\sim 70$ to $85 \mathrm{wt} \%$, with a few exceptions (Appendix I).

The RME enrichment (CI normalized; Fig. 7b) patterns of the 5 nuggets although show a strong Mo depletion, $\mathrm{W}$ depletion is not pronounced in all the nuggets, at least one nugget shows $\mathrm{W}$ enrichment relative to CI composition. Although data is available for only 5 nuggets, however, it is discernible that the elemental ratios do not show a wide spread (Fig. 8b) and are close to chondritic. 
Further, the elements $\mathrm{Ru}, \mathrm{Pt}$, $\mathrm{Rh}$ show a pattern closer to $\mathrm{CI}$ chondritic and their weight percentages are much higher than in the nuggets of the I-type spherules. Therefore, the segregation mechanism for RME from a mixture of metal and silicate seems much more efficient with respect to the volatile PGE, and this also implies that there could be an absence of PGE fractionation during atmospheric entry into refractory (Os, Ir, Ru) and volatile PGE (Pt, Rh, Pd), as observed in the nuggets in the Itype spherules (Rudraswami et al., 2011). Further, nugget formation in the G-type spherules has taken place under less heating and oxidation compared to I-type spherules if one goes by the higher percentages of the volatile elements in the nuggets. The Ir versus Os and Pt versus Rh show positive correlation which is similar to the RMNs in the I-type spherules. However, it is difficult to see a correlation in Pt and Ru versus Os due to the limited data available (Fig. 10).

Parashar et al. (2010) presented analysis on three G-type spherules, which showed the wt\% contents to be $\mathrm{MgO}(10.4 \pm 3.1), \mathrm{Al}_{2} \mathrm{O}_{3}(0.7 \pm 0.4), \mathrm{SiO}_{2}(17.5 \pm 5.5), \mathrm{CaO}(0.7 \pm 0.1), \mathrm{Cr}_{2} \mathrm{O}_{3}$ (0.56), $\mathrm{FeO}(68.9 \pm 6.2)$, and $\mathrm{NiO}$ (4.7). They also analyzed the matrix of G-type spherules which showed high $\mathrm{CaO}$ contents $(6-9 \mathrm{wt} \%)$, but the $\mathrm{Al}$ contents were not as high as in D-P14-II. It appears that D-P14-II, in view of its high Al content, could have been derived from an Al-rich mineral in the parent body of this spherule. However, the Fe/Ni ratios in four of the G-type spherules from the present study have values of $\sim 1.0-1.6$ (atomic values normalized to $\mathrm{CI}$ ), excluding one which has 3.2, suggesting a majority of the spherules are chondritic.

\subsection{Nuggets in S-type spherules}

The present study has 643 S-type spherules, out of which 511 are barred olivine spherules. The other textural types are in smaller numbers: porphyritic (92), scoriaceous (11), cryptocrystalline (11), glass (16) and a lone Ca-rich spherule. Out of the 643 S-type spherules, the 20 which showed the presence of RMNs are barred olivine spherules, apart from the Ca-rich spherule. A majority of the nuggets exhibit a spherical shape, while some of them are slightly irregular (Figs. 4 and 5). The size of the nuggets is uniformly smaller when compared with those in I- and G-type spherules. The nugget in D-P98 (diameter $\sim 2.5 \mu \mathrm{m}$ ) is spherical, similar to the ones found in I-type spherules and is located near the edge of the spherule, although the nuggets in barred olivine spherules tend to be positioned in all regions of the spherule. In all, 26 nuggets were found in the S-type spherules, with sizes ranging from $\sim 0.5 \mu \mathrm{m}$ to $\sim 3 \mu \mathrm{m}$. The barred olivine spherules were not examined for surface occurrence of nuggets (only polished sections were examined) as it is difficult to recognize nuggets on their surfaces. While 17 spherules had one nugget each, three spherules D-P55 (diameter 265 
$\mu \mathrm{m})$, D-P34 $(\sim 306 \mu \mathrm{m})$ and D-P287 $(\sim 295 \mu \mathrm{m})$ contain 2, 4 and 2 nuggets, respectively (Table 2). Note that multiple nuggets are observed only in barred olivine spherules, but not in I- or G-type spherules. The nuggets in S-type spherules are generally smaller in size and require careful inspection under the SEM. There are, however, a very small number of nuggets that are larger than $\sim 2 \mu \mathrm{m}$. The RME data of these nuggets are given in Table 2 and the bulk chemical compositions of the host spherules are provided in Appendix I. The RME compositions of the multiple nuggets in barred olivine spherules vary significantly. Interestingly, Bonte et al. (1987) observed 9 nuggets in a lone barred olivine spherule and the compositions of all them were different, none conforming to chondritic ratios.

Twenty six nuggets from 20 spherules are plotted with respect to decreasing volatility of RME (Fig. 7c). One of the striking features of this plot is the enrichment or lack of depletion of $\mathrm{W}$ in many when compared with the nuggets in I- and G-type spherules. Further, most of the RME have compositions that are close to chondritic (CI), and only Pd and to a certain extent Rh appear to be depleted. Mo is uniformly depleted in all the nuggets observed so far. Further, the CI chondrite normalized elemental ratios of $\mathrm{Os} / \mathrm{Ir}, \mathrm{Ru} / \mathrm{Ir}, \mathrm{Rh} / \mathrm{Ir}, \mathrm{Pt} / \mathrm{Ir}, \mathrm{Pt} / \mathrm{Os}$ are all close to chondritic ratios, whereas, $\mathrm{Pd} / \mathrm{Ir}$ shows a dip and Pt/Pd an enrichment because of the volatilization of Pd (Fig. 8c). The plots of Ir versus Os and Pt versus Rh show a positive correlation similar to those found in nuggets of I- and G-type spherules. Further, negative correlation is observed with respect to Pt and Ru versus Os which is similar to that in the nuggets in the I-type spherules, however the slope is much steeper in the present case (Fig. 11).

D-P15 is a rare spherule having an irregular-shaped nugget of size $1.4 \times 0.6 \mu \mathrm{m}$ (Fig. 5). This $\sim 140 \mu \mathrm{m}$ spherule is Ca-rich with a bulk chemical composition of $\mathrm{CaO} \sim 17 \mathrm{wt} \%, \mathrm{MgO} \sim 16 \mathrm{wt} \%$, $\mathrm{Al}_{2} \mathrm{O}_{3} \sim 2.3 \mathrm{wt} \%, \mathrm{SiO}_{2} \sim 32.1 \mathrm{wt} \%$ and $\mathrm{FeO} \sim 31.2 \mathrm{wt} \%$ (Table 4a). An irregular shaped nugget is enclosed in a Fe-Ni rich phase surrounded by sulfide phases with sulfide content as high as $\sim 38 \%$ (Fig. 5 and Table 4b). The sulfide content becomes insignificant moving out a few $\mu \mathrm{m}$. The Fe-Ni bead encasing the nugget has a PGE composition distributed homogeneously in the bead. This form of nugget embedded in the complex Fe-Ni-S phase is similar to opaque assemblages found in the CAIs of CV chondrites (Brearley and Jones, 1998). The heavy PGEs like Os, Ir and Pt are enriched compared to others such as $\mathrm{Ru}$ with a complete depletion of $\mathrm{Rh}$ and Pd (Fig. 7c; dark line joining filled square). This nugget is depleted in elements like $\mathrm{W}$ and Mo (Table 2). 


\section{DISCUSSION}

RMNs are observable in all the three basic types of cosmic spherules, there are however differences in their sizes, modes of occurrence and their elemental distribution patterns. The average nugget diameter decreases from those in I-type $(4.70 \pm 1.63 \mu \mathrm{m}$ for 26 nuggets) through G-type $(3.9 \pm 2.25 \mu \mathrm{m}$ for 5 nuggets) to the S-type $(1.50 \pm 0.63 \mu \mathrm{m}$ for 26 nuggets). There is no major difference in the average spherule diameters which host these nuggets (average diameters: I-type spherules $=216 \pm 42 \mu \mathrm{m}$ for 23 spherules; S-type $=256 \pm 59 \mu \mathrm{m}$ for 20 spherules; G-type $=240 \pm 66 \mu \mathrm{m}$ for 5 spherules). If one goes by the size of the RMNs, it appears that the I-type spherules are most efficient in metal segregation. They also show a positive correlation in the Os versus Ir ratios (Fig. 9a) which is in tune with chondritic ratios, and a positive correlation with respect to Pt versus $\mathrm{Rh}$ ratios (Fig. 9b) maybe because these two elements have similar volatility. However, a negative correlation with respect to Pt versus Os (Fig. 9c) is observed because Pt is relatively more volatile or is distributed among the nanometer sized nuggets which are spread throughout the spherule. Also correlation between $\mathrm{Ru}$ and Os also seems to be negative (Fig. 9d). The partitioning of the RMNs into a refractory $(\mathrm{Os}, \mathrm{Ir}, \mathrm{Ru})$ and a volatile $(\mathrm{Pt}, \mathrm{Rh}, \mathrm{Pd})$ nuggets seems to be happening only in these spherules.

The condensation temperatures of $\mathrm{Pt}$ and $\mathrm{Rh}$ are closer to that of $\mathrm{Ni}$ therefore a selective uptake of $\mathrm{Pt}$ and $\mathrm{Rh}$ by $\mathrm{Ni}$ in the nanometer nuggets seems to take place in the I-type spherules. This process could also be caused by the differences in the crystal structures of the individual elements. For example, Palme and Wlotzka (1976) suggested in a cooling alloy of comprising of RMNs, Ru and Os would crystallize into a hexagonal close packed (hcp) whereas Ir, Pt, Co, Ni and Fe would form a face-centered cubic (fcc) alloy and therefore are more compatible with Ni. This process could be one of the reasons for the Pt enrichment in the nanometer size nuggets. Further, the volatile $\mathrm{Pd}$ is depleted to the maximum in the nuggets in the I-type spherules when compared to those in the G-and S-type spherules, which suggests that the I-type spherules have undergone the maximum heating among all the spherules. While $\mathrm{W}$ and Mo are also depleted in these nuggets, it is difficult to ascribe their depletion to only to heating (although Mo is relatively volatile ) because $\mathrm{W}$ and Mo oxidize much easier than the PGE and $\mathrm{W}$ also tends to migrate subsequently to the surrounding parts (Palme, 1994).

Nuggets in I-type spherules were discovered by Brownlee et al (1984), they suggested a mechanism where the nugget formation takes place due to the pulse heating that takes place during 
atmospheric entry. The mechanism involves metal segregation in a chondritic parent body due to heating leading to pyrolysis (in view of the presence of carbon in these bodies). Continuation of the heating and subsequent oxidation, the elements that are not oxidizable and noble would segregate into nuggets (Brownlee et al. 1984). The elemental ratios and enrichment patterns observed by them showed near chondritic ratios for the refractory RME with progressive depletion of the more volatile RME. Therefore they suggested that the nuggets are fractionated from a chondritic body. The chondrite normalized elemental ratios of the RMNs in the I-type spherules are similar to the patterns shown by Brownlee et al. (1984), thereby suggesting a similar mechanism and provenance for these nuggets.

The metal enrichment patterns of the nuggets in the G-type spherules are also similar to those in the I-type except for the higher concentrations of $\mathrm{Ru}, \mathrm{Pt}$, and $\mathrm{Rh}$ which are close to chondritic in composition. Therefore, apparently the formation mechanism of these nuggets also follows a pathway of metal segregation as outlined by Brownlee et al. (1984).

Among the more "disequilibrated" nuggets are those in the barred olivine spherules. Bonte et al. (1987) identified 9 nuggets in one barred olivine spherule, all of them had different compositions and none of them conformed to chondritic compositions, they called these as "disequilibrated". However, they opined the bulk composition of these nuggets together should conform to chondritic compositions. The enrichment patterns of the nuggets in the S-type spherules in the present investigation show broadly chondritic patterns, however, there is enrichment of $\mathrm{W}$ in some of them which is not seen elsewhere (Figs 6 and 7). The heating and oxidation undergone by these spherules has been insufficient to oxidize $\mathrm{W}$, this is supported by the high Fe contents of the host spherules. Nearly all the barred olivine spherules containing nuggets have a bulk $\mathrm{FeO}$ composition varying from $\sim 25 \mathrm{wt} \%$ to $45 \mathrm{wt} \%$, suggesting that nuggets tend to occur in $\mathrm{FeO}$ rich spherules, similar to those found by Bonte et al. (1987). The average FeO contents of 21 nuggetbearing barred olivine spherules is $\sim 35 \mathrm{wt} \%$, which is much higher than the average of $\sim 30 \mathrm{wt} \% \mathrm{FeO}$ analyzed for 62 barred olivine spherules from an unbiased collection by us (Prasad et al. 2013), and $26.6 \pm 4.6 \mathrm{wt} \% \mathrm{FeO}$ for 46 barred olivine spherules analyzed by Taylor et al. (2000). Therefore, high Fe content appears to be one of the pre-requisites for nugget formation. However, Taylor et al. (2000) suggested that the texture of the spherules changes with increasing Fe volatilization, the more volatilized spherules having cryptocrystalline and glassy textures and much lower Fe content than the barred ones. The presence of higher $\mathrm{FeO}$ in the spherules in the present study also suggests that they have not undergone the amount of heating experienced by the barred olivine spherules from 
other collections (e.g. Brownlee et al., 1997). Chondrite normalized major element ratios (atom) of all the barred olivine spherules show a CI chondritic composition particularly for $\mathrm{Fe}$ and $\mathrm{Mg}$, whereas Al appears to be depleted and Ca shows a scatter (Fig. 12). In contrast, Brownlee et al. (1997) found Fe depletion with respect to CI values in 500 cosmic spherules. While high Fe content seems to be a consistent factor for the formation of nuggets in the spherules (with the exception of D-P98, refer Appendix-1), there appears to be no evidence of a correlation between bulk chemical compositions, nugget compositions, nugget size and spherule diameter.

Temperatures greater than $\sim 1200^{\circ} \mathrm{C}$ were required to produce completely melted cosmic spherules without vesicles accompanied by iron loss, when sub-mm particles of Murchison were heated under conditions simulating atmospheric entry (Toppani et al., 2001) and $\sim 1700^{\circ} \mathrm{C}$ is the maximum any spherule can be heated without vaporizing completely (Love and Brownlee, 1991). These are the defining conditions of heating undergone by the spherules which enabled nugget formation from a chondritic precursor.

Other than cosmic spherules, RMNs have been found originally in CAIs in carbonaceous chondrites. After they were discovered (Palme and Wlotzka, 1976), detailed investigations have been carried out by several groups. Substantial portions of the refractory metal nuggets in chondrites are found in refractory CAIs that condensed early in the solar nebula (Grossman, 1972, 1980; Palme and Wlotzka, 1976; El Goresy et al., 1978; Wark and Lovering 1978; Sylvester et al., 1993). The nuggets in CAIs are interpreted as high temperature condensates that were initially formed and later incorporated into CAIs during their formation (El Goresy et al., 1978). We compared the RME enrichment patterns and element ratios with the nuggets in the CAIs reported in the literature (Figs 7 and 8). The nugget formation in CAIs were ascribed to the condensation of refractory metals (W, Mo Re and PGE), followed by oxidization of $\mathrm{W}$ and Mo (Bischoff and Palme, 1987). The nuggets in S-type spherules and indeed in all the spherules in this investigation have undergone pulse heating $(\sim 5-15 \mathrm{sec})$ between the spherule forming temperatures of $1200-1700^{\circ} \mathrm{C}$ of a chondritic precursor body. The enrichment patterns and the elemental ratios in S-type spherules show conformity with chondritic ratios and the subsequent oxidation apparently has not been totally efficient for removal of $\mathrm{W}$ in the nuggets.

The CI chondrite normalized PGE ratio of the Os/Ir in the nuggets of cosmic spherules studied by us and those from Brownlee et al. (1984), Kurat et al. (1994) are close to $\sim 1$. The other ratios (Ru/Ir, $\mathrm{Rh} / \mathrm{Ir}, \mathrm{Pd} / \mathrm{Ir}, \mathrm{Pt} / \mathrm{Ir}, \mathrm{Pt} / \mathrm{Os}, \mathrm{Pt} / \mathrm{Rh}, \mathrm{Pt} / \mathrm{Ru}, \mathrm{Pt} / \mathrm{Pd}$ ) gradually deviate from chondritic and show a large 
spread where relative condensation temperatures of RME seems to be the controlling factor (Fig. 8). This pattern is more pronounced in case of nuggets in the I-type spherules when compared with Gand S-types (Fig. 8). The nuggets in CAIs (Fig. 8d) do not allow comparisons to be drawn due to the large spread in their elemental ratios (e.g. Palme and Wlotzka, 1976; Wark and Lovering, 1978; Berg et al., 2009), and depletion of $\mathrm{Pd}$ and/or Rh, unlike in the case of cosmic spherules. The presence of volatile elements like Pd and Rh in many nuggets of cosmic spherules, and absence of Mo (Fig. 7) in almost all the nuggets in spherules may indicate that the Mo experienced a high temperature oxidation environment (Köhler et al., 1988; Palme et al., 1994).

In view of the discussions presented above, it can be concluded that the bulk chemistry of the host spherules (Fig. 12) and the nugget chemistry (Figs. 6-11) point towards carbonaceous chondrites as precursors.

\section{1. $\mathrm{RMN}$ in D-P15 a fremdling?}

D-P15 appears to be S-type spherule by composition in view of its lithophile contents and contains a nugget which is enclosed in a Fe-Ni and sulfide phase. However, texturally, it has a glassy internal texture with dendritic magnetites and in appearance somewhat similar to G-type spherules except that the magnetite dendrites are fewer in number. Its bulk chemistry appears to be chondritic, although $\mathrm{Mg}$ is somewhat low, the other major oxides have percentages within the range given for barred olivine spherules (Taylor et al., 2000; Brownlee et al. 1997; Prasad et al., 2013). The presence of nickel also confirms its cosmic origin (Table 4). The high $\mathrm{CaO}$ content $(16.8 \%)$ of this spherule does not match with any known cosmic spherules type. This spherule together with the enclosed nugget appears to be unique and is discussed separately here. The nugget in this spherule is multifaceted and complex (Fig. 5). The morphology of the nugget bears a resemblance to the fremdlinge observed in the CAIs of CV chondrites. Fremdlinge are multifaceted bodies consisting of metal, phosphate, sulfide and RMNs (El Goresy et al., 1978; Palme et al., 1982; Wark and Lovering 1982; Brearley and Jones, 1998; Palme and Wlotzka, 1976; El Goresy et al., 1978; Blander et al., 1980; Armstrong et al., 1985; Bischoff and Palme, 1987; Blum et al., 1988, 1989; Zinner et al., 1991; Palme, 2008). Many researchers argued for their formation before the CAIs by nebular condensation and under condition of varying temperatures and oxygen fugacity during early solar nebula (El Goresy et al., 1978; Armstrong et al., 1985). Alternatively, they have also been suggested to have formed in CAIs under low temperatures, and high oxygen and sulfur fugacities (Blum et al, 1988; Palme et al. 1994, 1998). 
The chemical composition of the nugget in D-P15 (Table 4) which is enclosed in a Fe-Ni casing which is in turn is enclosed within a sulphide cover measuring $\sim 10 \mu \mathrm{m}$ (Fig. 5). The presence of large percentages of sulphur in this nugget provides constraints on the maximum heating experienced during entry. Further, the morphology of the nugget in D-P15 and the chemical layering within the nugget bear a strong resemblance to the fremdlinge observed in CAIs (Palme and Wlotzka, 1976; El Goresy et al., 1978; Armstrong et al., 1985). This prompts us to suggest the possibility that this nugget could be a fremdling. The Fe-Ni content in the nugget is greater than 60 wt\% similar to that found in Allende (Palme and Wlotzka, 1976; Armstrong et al., 1985). This similarity extends to the elemental ratios as well. The Os/Ir ratios of this nugget (Fig. 8c) are in the range observed for fremdlinge in CAIs (Fig. 8d). Further, Pt/Ir, Pt/Os of this nugget broadly occur in the range seen for nuggets in CAIs. The elemental abundance ratios of Os/Ir and $\mathrm{Pt} / \mathrm{Ru}$ normalized to CI values are 1.23 and 1.18, above the cosmic abundance. Importantly, this nugget shows a deviation in the elemental ratios when compared with all the other nuggets in the present study, especially with respect to a majority of the nuggets in the S-type spherules (Fig. 8c). However, the bulk chemistry of the host spherule does not match with any known CAIs.

We have made use of the Chemical Ablation Model (CABMOD) (Vondrak et al., 2008) to understand the factors, particularly zenith angle and entry velocity, that would have played an important role in preserving the complex structure of particle D-P15 during atmosphere entry, so that the particle did not undergo significant melting and ablation. That is, the presence of large $(\mathrm{Fe}, \mathrm{Ni}) \mathrm{S}$ regions in D-P15 constrain the peak temperature to the sulfur vaporization temperature of $\sim 650 \mathrm{~K}$. The model predicts complete preservation of the elemental composition of the meteoroid which has a mass of $\sim 3 \mu \mathrm{g}$, if the entry zenith angle was at least $70^{\circ}$ for a minimum velocity of $11 \mathrm{~km} \mathrm{~s}^{-1}$; higher entry velocities would have required even larger zenith angles. The region where there is no effective ablation and therefore the elemental composition is expected to be preserved, is shown in Fig. 13. In some cases without ablation the temperature rises $\sim 1400 \mathrm{~K}$, which would change the morphological features of the fremdling. However, in such case only faster cooling can preserve the recycling of material and more importantly the characteristic features of the nugget.

\section{SUMMARY AND CONCLUSIONS}

After systematically sectioning and sequentially polishing 992 magnetically collected cosmic spherules from the deep seafloor of the Indian Ocean, RMNs have been discovered in all the three basic types of cosmic spherules. Nuggets found in the I-type spherules support their formation 
during extreme heating and complete oxidation of spherules during atmospheric entry, and show a sequence of fractionation from a chondritic source. We discovered nuggets for the first time in Gtype spherules, they contain all the six PGE and show trends that are similar to those of nuggets in the I-type spherules. Therefore, the compositions and elemental ratios suggest that they could indeed have formed by similar mechanisms as the nuggets in the I-type spherules.

Nuggets in S-type spherules are not always spherical, and their chemical compositions are highly variable. The nuggets in barred olivine spherules may have been formed during atmospheric entry. The spherules hosting the nuggets show a chondritic bulk composition. Large scale siderophile depletion is not observed, rather the Fe contents are higher than conventional barred olivine spherules.

One spherule, D-P15 suggests the rare possibility of being a fremdling. This spherule contains a nugget which is encased in Fe-Ni metal which in turn is enveloped in a sulfur-rich phase. However, its bulk chemistry is not similar to that of a CAIs where fremdlinge are commonly reported. The finding of more such nuggets in spherules could provide clarity on the origin and formation of such objects.

\section{ACKNOWLEDGEMENTS}

NGR and MSP thank the Director of National Institute of Oceanography, Goa, for support. This work is supported by the Physical Research Laboratory, Ahmedabad, as a part of the PLANEX project (NGR and MSP). The quality of the manuscript has been improved from reviews by $\mathrm{H}$. Palme and an anonymous reviewer. We thank A. B. Valsangkar for the help at sea during the collection of spherules, and A.V. Sonawane for magnetic assembly and, Vijay Khedekar for EPMA analysis. The CAMBOD model calculation are funded by UK NERC grant NE/G019487/1. This is NIO's contribution No. 


\section{REFERENCES}

Armstrong J.T., Goresy A. El. and Wasserburg G.J. (1985) Willy: A prize noble Ur-Fremdling-lts history and implications for the formation of fremdlinge and CAI, Geochim. Cosmochim. Acta 49, 1001-1022.

Bates B. A. (1986) The elemental composition of stony extraterrestrial particles from the ocean floor. Ph.D. thesis. University of Washington. 199 pp.

Beckerling W. and Bischoff A. (1995) Occurrence and composition of relict minerals in micrometeorites from Greenland and Antarctica-implications for their origins. Planet. Space Sci. 43, 435-449.

Berg T., Maul J., Schönhense G., Marosits E., Hoppe P., Ott U. and Palme H. (2009). Direct evidence for condensation in the early solar system and implications for nebular cooling rates. Astrophy. Jour. Lett. 702(2), L172.

Bischoff A. and Palme H. (1987) Composition and mineralogy of refractory-metal-rich assemblages from a Ca,Al-rich inclusion in the Allende meteorite. Geochim. Cosmochim. Acta 51, 27332748.

Blanchard M. B., Brownlee D. E., Bunch T. E., Hodge P. W. and Kyte F. T. (1980) Meteoroid ablation spheres from deep-sea sediments. Earth Planet. Sci. Lett. 46, 178-190.

Blander M., Fuchs L. H., Horowitz C. and Land R. (1980) Primordial refractory metal particles in the Allende meteorite. Geochim. Cosmochim. Acta 44, 217-223.

Blum J. D., Wasserburg G. J., Hutcheon I. D., Beckett J. R. and Stolper E. M. (1989) Origin of opaque assemblages in CV3 meteorites: Implications for nebular and planetary processes. Geochim. Cosmochim. Acta 53, 543-556.

Blum J. D., Wasserburg G. J., Hutcheon I. D., Beckett J. R. and Stolper E. M. (1988) Domestic origin of opaque assemblages in refractory inclusions in meteorites. Nature 331, 405-409.

Bonte Ph., Jehanno C., Maurette M. and Brownlee D. E. (1987) Platinum metals and microstructure in magnetic deep sea cosmic spherules. J. Geophy. Res. 92, 641-648.

Brearley A. J. and Jones R. H. (1998) Chondritic meteorites. In Planetary Materials (ed. J. J. Papike). Reviews in Mineralogy 36, pp. 3-1 to 3-398.

Brownlee D. E., Bates B. A. and Wheelock M. M. (1984) Extraterrestrial platinum group nuggets in deep-sea sediments. Nature 309, 693-695.

Brownlee D. E., Bates B. and Schramm L. (1997) The elemental composition of stony cosmic spherules. Meteorit. Planet. Sci. 32, 157-175.

Campbell A.J., Simon S.B., Humayun M. and Grossman L. (2003) Chemical evolution of metal in refractory inclusions in CV3 chondrites Geochim. Cosmochim. Acta, 67, 3119-3134.

Cremonese G., Borin P., Martellato E., Marzari F. and Bruno M. (2012) New calibration of the micrometeoroid flux on earth. Astrophy. Jour. Lett. 749, L40. 
El Goresy A., Nagel K. and Ramdohr P. (1978) Fremdlinge and their noble relatives. Proc. Lunar Planet. Sci. Conf. 9, 1279-1303.

Engrand C., McKeegan K. D. and Leshin L. A. (1999) Oxygen isotopic compositions of individual minerals in Antarctic micrometeorites: Further links to carbonaceous chondrites. Geochimica et Cosmochimica Acta 63, 2623-2636.

Genge M. J. and Grady M. M. (1998) Melted micrometeorites from Antarctic ice with evidence for the separation of immiscible Fe-Ni-S liquids during entry heating. Meteorit. Planet. Sci. 33, $425-434$.

Genge M. J., Engrand C., Gounelle M. and Taylor S. (2008) The classification of micrometeorites. Meteorit. Planet. Sci. 43, 497-515.

Greshake A., Klock W., Arndt P., Maetz M., Flynn G. J., Bajt S. and Bischoff A. (1998) Heating experiments simulating atmospheric entry heating of micrometeorites: Clues to their parent body sources. Meteor. Planet. Sci. 33, 267-290.

Grossman L. (1972) Condensation in the primitive solar nebula. Geochim. Cosmochim. Acta 36, $597-619$.

Grossman L. (1980) Refractory inclusions in the Allende meteorite. Ann. Rev. Earth Plan. Sci. 8, $559-608$.

Harries D., Berg T., Langenhorst F. and Palme H. (2012) Structural clues to the origin of refractory metal alloys as condensates of the solar nebula. Meteorit. Planet. Sci. 12, 2148-2159.

Hezel D. C., Russell S. S., Ross A. J. and Kearsley A. T. (2008) Modal abundances of CAIs: Implications for bulk chondrite element abundances and fractionations. Meteor. Planet. Sci. 43, 1879-1894.

Herzog G. F., Xue S., Hall G. S., Nyquist L. E., Shih C.-Y., Wiesmann H., and Brownlee D. E. (1999) Isotopic and elemental composition of iron, nickel, and chromium in type I deep-sea spherules: Implications for origin and composition of the parent micrometeoroids. Geochim. Cosmochim. Acta 63, 1443-1457.

Hua X, Wang Y., Hsu W. and Sharp T. G. (2005) Fremdlinge in chondrules and matrix of the Ningqiang carbonaceous chondrite. Lunar Planet. Sci. XXXVI, Lunar Planet. Inst., Houston. \#1762 (abstr.).

Hutcheon I. D., Armstrong J. T. and Wasserburg G. J. (1987) Isotopic studies of Mg, Fe, Mo, Ru and $\mathrm{W}$ in Fremdlinge from Allende refractory inclusions. Geochim. Cosmochim. Acta 51, 31753192.

Köhler, A. V., Palme, H., Spettel, B. and Fegley, B. (1988) Fractionation of Refractory Metals by High Temperature Oxidation. Lunar Planet. Sci. XIX, Lunar Planet. Inst., Houston. pp. 627628 (abstr.).

Kurat G., Koeberl C., Presper T., Brandstatter F. and Maurette M. (1994) Petrology and geochemistry of Antarctic micrometeorites. Geochim. Cosmochim. Acta 58, 3879-3904. 
Love S. G. and Brownlee D. E. (1991) Heating and thermal transformation of micrometeoroids entering the Earth's atmosphere, Icarus 89, 26-43.

Love S. G. and Brownlee D. E. (1993) A Direct Measurement of the Terrestrial Mass Accretion Rate of Cosmic Dust. Science 262, 550-553.

Palme H. and Wlotzka F. (1976) A metal particle from a Ca,Al-rich inclusion from the meteorite Allende, and the condensation of refractory siderophile elements. Earth Planet. Sci. Lett. 33, 45-60.

Palme H., Wlotzka F., Nagel K. and El Goresy A. ( 1982) An ultra-refractory inclusion from the Omans carbonaceous chondrite. Earth Planet. Sci. Lett. 61, 1-12.

Palme H., Hutcheon I. D. and Spettel B. (1994) Composition and origin of refractory-metal-rich assemblates in a Ca Al-rich Allende inclusion. Geochim. Cosmochim. Acta 58, 495-513.

Palme H., Borisov A. and Wulf A. V. (1998) Experimental Determination of the Oxidation Sequence of Refractory Metals. Lunar Planet. Sci. XXIX, Lunar Planet. Inst., Houston. \#1611 (abstr.).

Palme H. (2008) Platinum-group elements in cosmochemistry. Elements 4, 233-238.

Parashar K., Shyam Prasad M. and Chauhan S. S. S. (2010) Investigations on a large collection of cosmic dust from the Central Indian Ocean. Earth Moon Planet. 107, 197-217.

Peucker-Ehrenbrink B. and Ravizza G. (2000). The effects of sampling artifacts on cosmic dust flux estimates: a reevaluation of nonvolatile tracers (Os, Ir). Geochim. Cosmochim. Acta 64, 1965-1970.

Plane J. M. C. (2012) Cosmic dust in the earth's atmosphere. Chem. Soc. Rev. 41, 6507-6518.

Prasad M. S., Rudraswami N G. and Panda D. K. (2013), Micrometeorite flux on Earth during the last 50,000 years, J. Geophys. Res. Planets, 118, 1-19, doi:10.1002/2013JE004460.

Robin E., Jéhanno C. and Maurette M. (1988) Characteristics and origin of greenland Fe/Ni cosmic grains. Lunar Planet. Sci. XVIII, Lunar Planet. Inst., Houston, 593-598.

Rudraswami N.G., Shyam Prasad M., Babu E.V.S.S.K., Vijaya Kumar T., Feng W. and Plane J.M.C. (2012) Fractionation and fragmentation of glass cosmic spherules during atmospheric entry. Geochim. Cosmochim. Acta 99, 110-127.

Rudraswami N. G., Parashar K. and Shyam Prasad M. (2011) Micrometer and nanometer size platinum group nuggets in micrometeorites from the deep sea sediments of Indian Ocean. Meteorit. Planet. Sci. 46, 470-491.

Sylvester P. J., Simon S. B. and Grossman L. (1993) Refractory inclusions from the Leoville, Efremovka, and Vigarano C3V chondrites: Major element differences between Types A and B, and extraordinary refractory siderophile element composition. Geochim.Cosmochim. Acta 57, 3763-3784. 
Tagle R. and Berlin J. (2008). A database of chondrite analyses including platinum group elements, $\mathrm{Ni}, \mathrm{Co}, \mathrm{Au}$, and $\mathrm{Cr}$ : Implications for the identification of chondritic projectiles. Meteorit. Planet. Sci. 43, 541-559.

Taylor, S., Lever, J. H. and Harvey, R. P. (1998) Accretion rate of cosmic spherules measured at the South Pole. Nature 392, 899-903.

Taylor S., Lever J. H. and Harvey R. P. (2000) Numbers, types and compositions of an unbiased collection of cosmic spherules. Meteorit. Planet. Sci. 35, 651-666.

Toppani A., Libourel G., Engrand C. and Maurette M. (2001) Experimental simulation of atmospheric entry of micrometeorites. Meteorit. Planet. Sci. 36, 1377-1396.

Vondrak T., Plane J. M. C., Broadley S. and Janches D. (2008) A chemical model of meteoric ablation. Atmos. Chem. Phys. 8, 7015-7031.

Wark D . A. and Lovering J. F. (1982) The nature and origin of type BI and B2 Ca-Al-rich inclusions in the Allende meteorite. Geochim. Cosmochim. Acta 46, 2581-2594.

Wark D. A. and Lovering J. F (1976) Refractory/Platinum Metal Grains in Allende CalciumAluminium-Rich Clasts (Carc's): Possible Exotic Presolar Material?. Lunar Science VII, Lunar and Planetary Inst, Houston, pp. 912-914

Wark D. A. and Lovering J. F (1978) Refractory /Platinum metals and other opaque phases in Allende Ca-Al-rich inclusions (CAI's). Lunar and Planetary Science IX, Lunar and Planetary Inst, Houston, pp. 1214-1216.

Wasson J. T. and Kallemeyn G. W. (1988) Compositions of Chondrites. phil. trans. royal society of london 325, 535-544.

Zinner E. K., Caillet C. and Goresy A. El. (1991) Evidence for extraneous origin of a magnesiowustite-metal Fremdling from the Vigarano CV3 chondrite. Earth Planet. Sci. Lett. 102, 252-264. 


\section{FIGURE CAPTIONS}

Fig. 1. RMNs in some of the I-type spherules which have different proportions of wustite and magnetite. The dark portions in the spherules are magnetite and light grey areas are wustite. Note the dark magnetite phases dominate in all the spherules that contain nuggets. Complete oxidation during atmospheric entry has led to such a large magnetite formation, and the unoxidized refractory metals within the spherules have segregated into nuggets. An enlarged view of the nugget in D-P218 shown in (f) has an irregular shaped small nugget attached to the main nugget.

Fig. 2. RMNs seen on the outer surface of I-type spherules. Images on the right side are magnified versions of the nuggets shown on the respective spherules. The grey fan-like feature on D-P10 (b) is an artefact.

Fig. 3. RMNs in G-type spherules. An enlarged view of each nugget is shown on the right hand side. G-type spherules are known to comprise of dendritic magnetites, a Fe-Ni metal bead in a glassy matrix. It can be noticed that the Fe-Ni metal bead and dendritic magnetites are almost completely absent in these spherules because of excessive heating and oxidation. The unoxidized refractory metals form into a nugget, in a similar fashion to those in the I-type spherules shown in Fig. 1. The nugget of D-P123 can be seen in the encircled region.

Fig. 4. RMNs in barred olivine spherules. An enlarged view of each nugget is shown on right hand side and is encircled. D-P34 is the barred spherule showing the presence of multiple nuggets. The spherules where nuggets can be observed are to a large extent unaffected by etching. In contrast to the nuggets in the I-type and G-type spherules, the nuggets here are not spherical.

Fig. 5. SEM image of D-P15 with a RMN. The spherule comprises of a glassy phase which is Carich and sparsely distributed dendritic magnetites. Enlarged views of the nugget are shown in Figs. $\mathrm{b}, \mathrm{c}$ and $\mathrm{d}$. The area marked number 1 in (b) is the glassy matrix, chemical composition of the matrix is given in Table 4. The region marked as 5 is the irregular shaped RMN enclosed in region 4 which is an Fe-Ni phase, and the entire metal-enriched area is surrounded by a sulfide phase marked as region 3. The chemical compositions of all these phases are given in Tables 2 and 4.

Fig. 6. Nanometer sized nuggets seen in I-type spherules. Images on the right side are magnified versions of the nuggets seen in the respective spherules. These nuggets occur only in the magnetite (dark phases) portions of the spherules and are enriched in $\mathrm{Pt}$, and $\mathrm{Rh}$.

Fig. 7. Nuggets from the spherules plotted according to decreasing condensation temperatures of RMEs. The data normalized with CI chondrite values are from Tagle and Berlin (2008). (a) The nuggets in I-type spherules show a close conformity with respect to Os and Ir but are depleted in W, Mo and markedly in the more volatile RME (Pt, Rh and Pd) (b) The RMNs in G-type spherules are relatively in greater conformity to chondritic ratios than those in the I-type spherules, the dark line joining filled squares outlines composition of fremdling-like nugget in D-P15 (c) The nuggets in Stype spherules have $\mathrm{W}$ enrichment in some of them. Os, Ir, Pt, $\mathrm{Ru}$ and $\mathrm{Pt}$ are much closer to chondritic ratios than in the other spherules. Mo is depleted uniformly in all the nuggets, so are $\mathrm{Rh}$ and Pd. The dark line joining filled squares in this figure belongs to the fremdling-like nugget in D- 
P15. (d) RMNs in CAIs when seen in isolation do not show any pattern, however, when RMNs from several investigations are plotted the overall metal enrichment pattern appears somewhat close to CI ratios, but markedly different from the patterns shown by the nuggets in cosmic spherules (Palme and Wlotzka, 1976; Wark and Lovering, 1976; Berg et al., 2009).

Fig. 8. Chondrite normalized RME ratios for nuggets all the three types of cosmic spherules compared with those in CAIs. The data normalized with CI chondrite values are from Tagle and Berlin (2008). (a) RMNs in I-type spherules : Os/Ir and Ru/Ir ratios appear to conform to chondritic ratios, however, the relatively volatile $\mathrm{RME}$ (eg. $\mathrm{Pd}, \mathrm{Pt}, \mathrm{Rh}$ ) versus refractory RME ratios shows a deviation from chondritic ratios which suggests volatile RME depletion. (b) RMNs in G-type spherules: Although data is for only 5 nuggets, a close conformity with respect to chondritic ratios is observed except for the most volatile RME ratios of $\mathrm{Pt} / \mathrm{Pd}$. (c) RMNs in S-type spherules: Majority of the elemental ratios are much closer to chondritic values than in the I-type spherules, the only strong deviation appears to be that of $\mathrm{Pt} / \mathrm{Pd}$. The volatile element $\mathrm{Pd}$ is depleted uniformly in all the nuggets. (d) RMNs in CAIs show a vast spread in the elemental ratios when compared with chondritic values, the element Pd is almost absent (Palme and Wlotzka, 1976; Wark and Lovering, 1976; Berg et al., 2009).

Fig. 9 : Element pairs in RMNs in I-type spherules. Positive correlation is seen for Ir versus Os, Pt versus Rh; whereas, negative correction is discernible with respect to Pt versus Os and to a certain extent $\mathrm{Ru}$ versus Os also.

Fig. 10. Element pairs in RMNs in G-type spherules, strong positive correlation is observed for $\mathrm{Ir}$ versus Os, to a certain extent in Pt versus $\mathrm{Rh}$ and $\mathrm{Pt}$ versus Os also. However, no correlation can be drawn for Pt and Ru versus Os.

Fig. 11. Element pairs in RMNs in S-type spherules. Positive correlation is observed with respect to Ir versus Os and $\mathrm{Pt}$ versus $\mathrm{Rh}$, whereas $\mathrm{Pt}$ versus $\mathrm{Os}$ and $\mathrm{Ru}$ versus Os show negative correlation. This is similar to the trends shown by the RMNs in I-type spherules (Fig. 9).

Fig. 12. Major element ( $\mathrm{Mg}, \mathrm{Al}, \mathrm{Ca}$ and $\mathrm{Fe}$ ) ratios (atom) of barred spherules having refractory metal nuggets normalized to $\mathrm{Si}$ and $\mathrm{CI}$ chondritic values. $\mathrm{CI}$ chondritic values are from Wasson and Kallemeyn (1988).

Fig. 13. The temperature achieved from a $\sim 140 \mu \mathrm{m}$ diameter spherule D-P15 as a function of zenith angle and velocity, predicted by CABMOD (Vondrak et al, 2008). 
Flg. 1
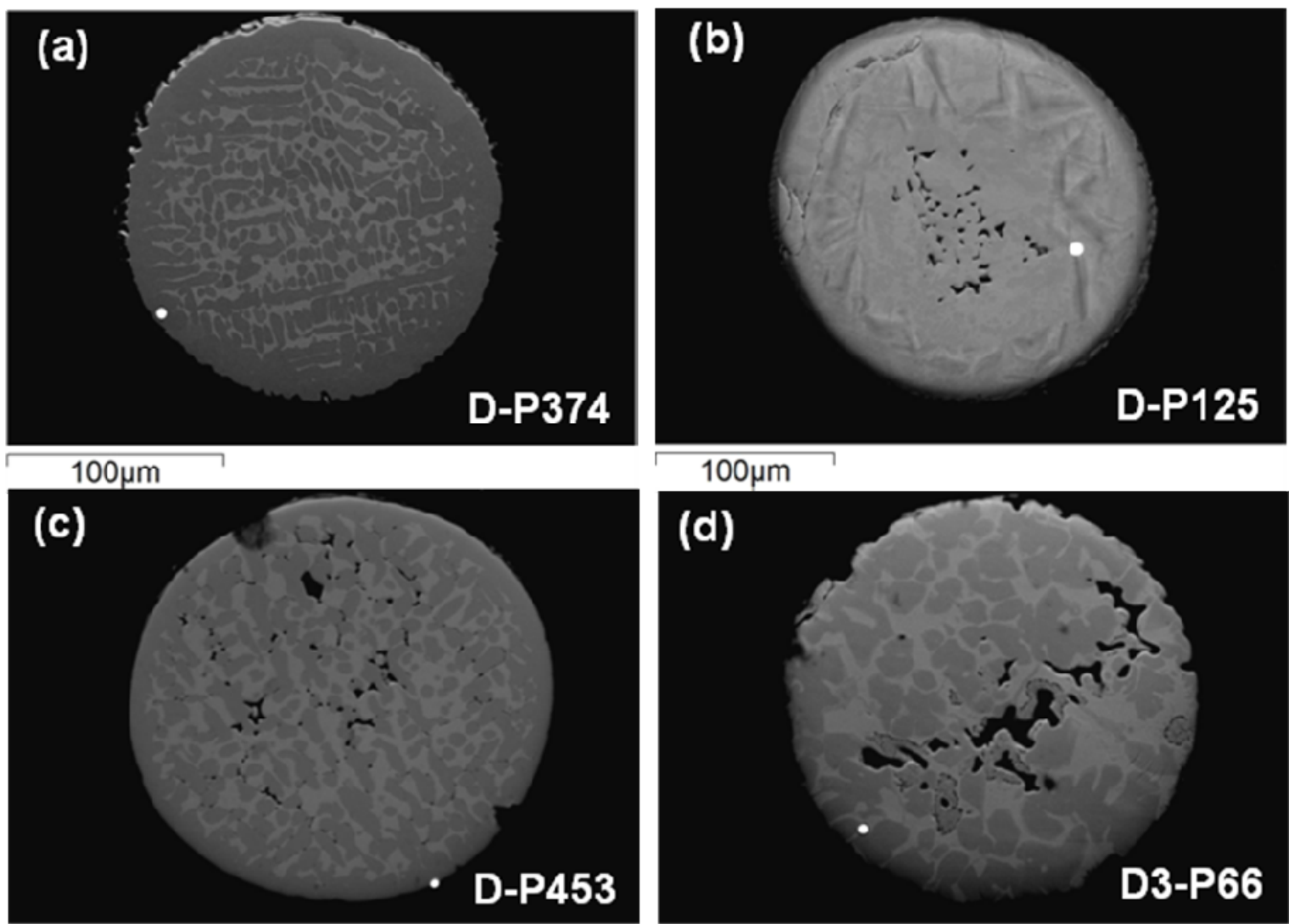

$100 \mu \mathrm{m}$
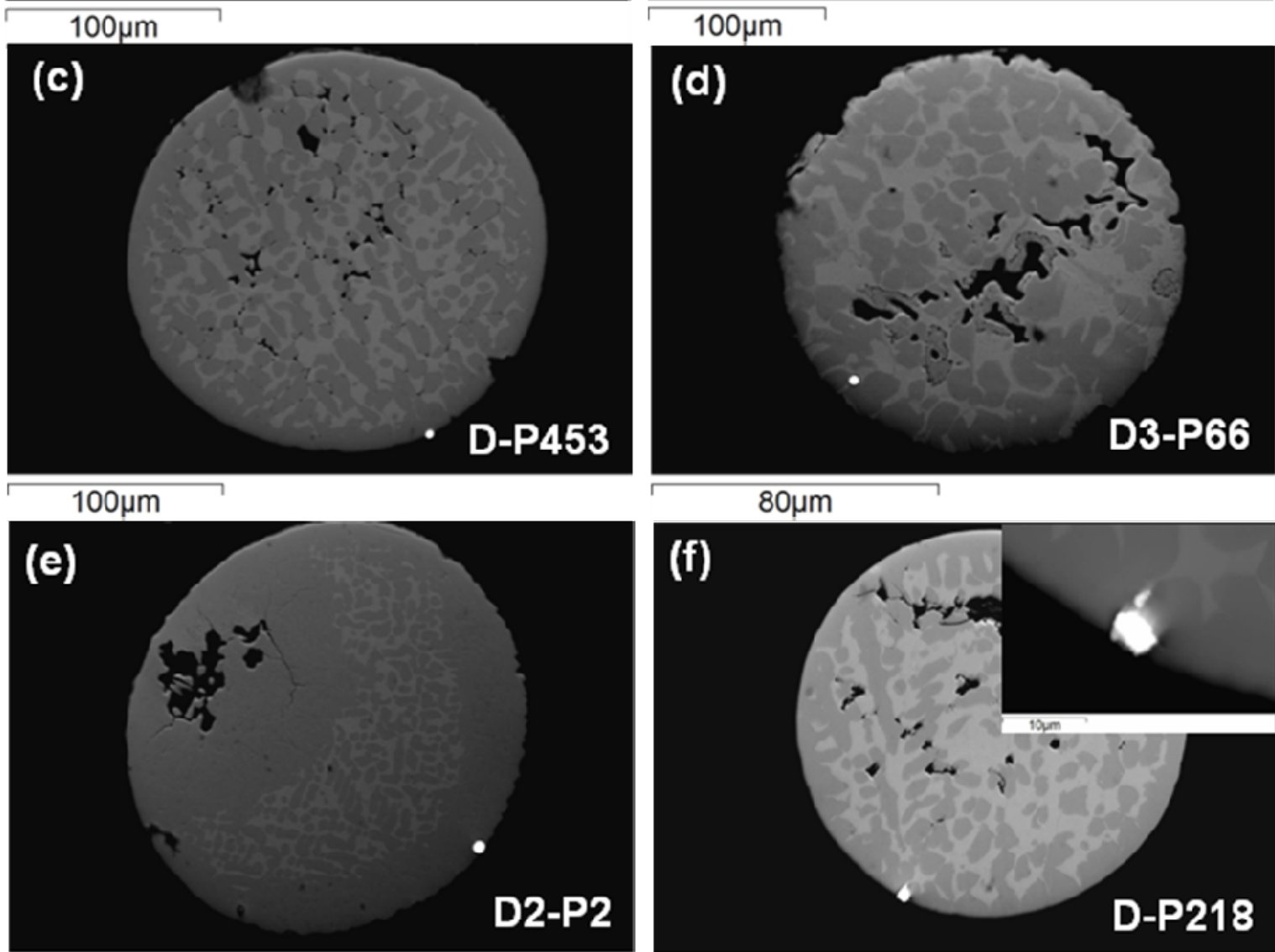

$100 \mu \mathrm{m}$

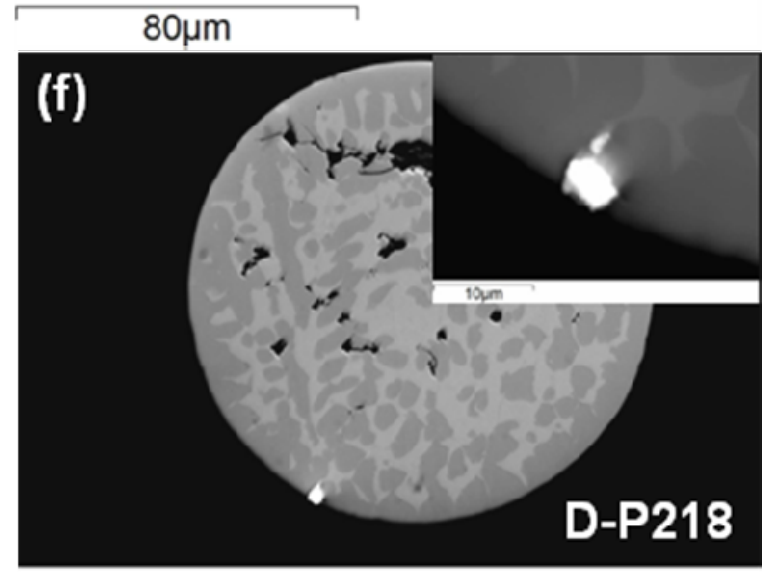

$100 \mu \mathrm{m}$ 
Fig. 2
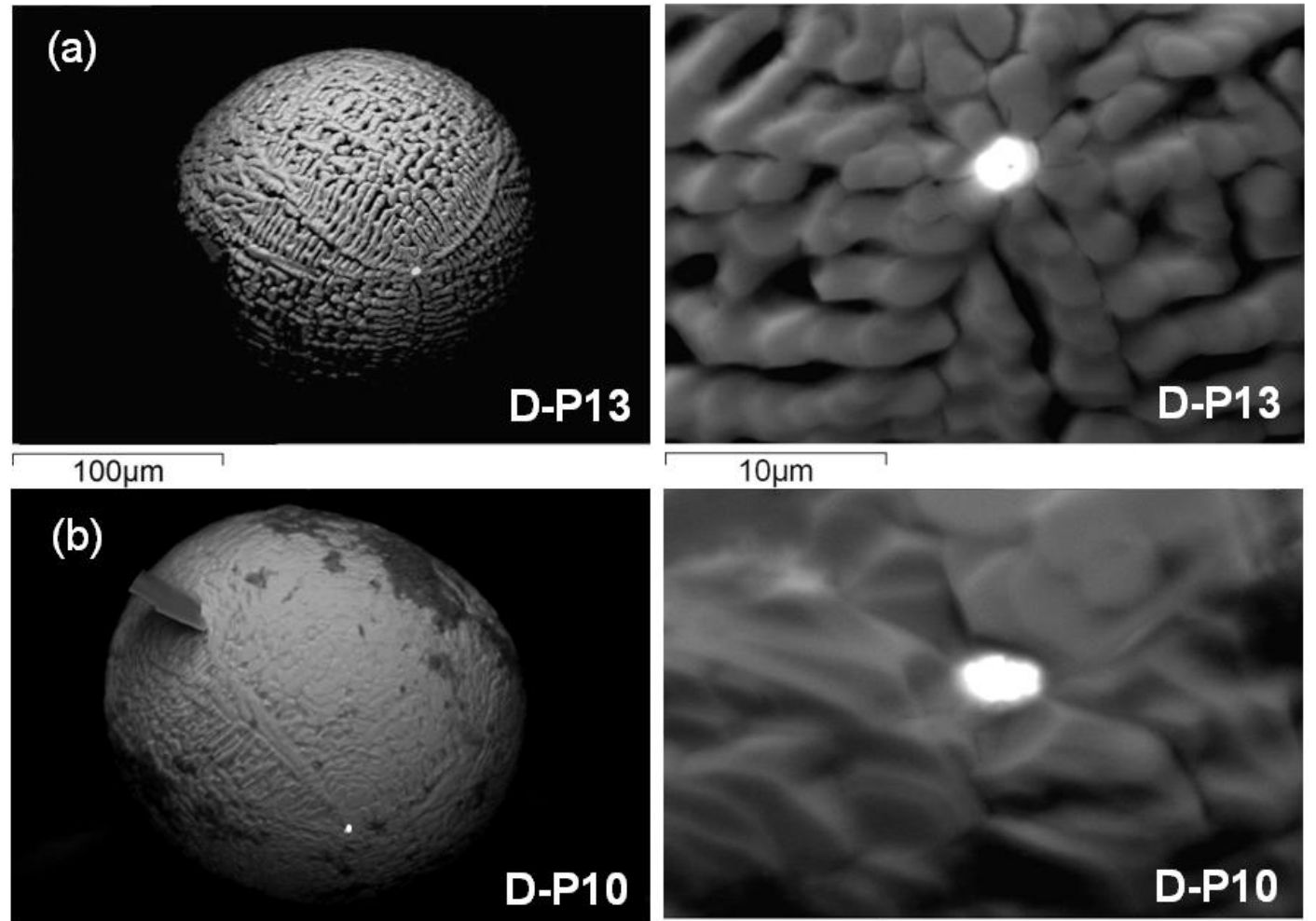

$100 \mu \mathrm{m}$

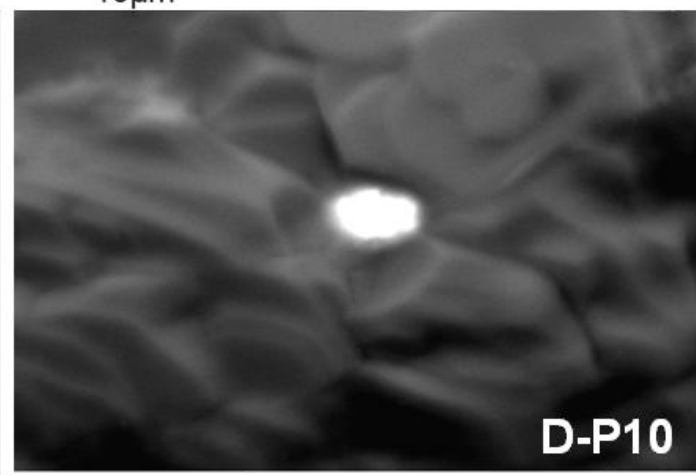

$10 \mu \mathrm{m}$ 
Fig. 3

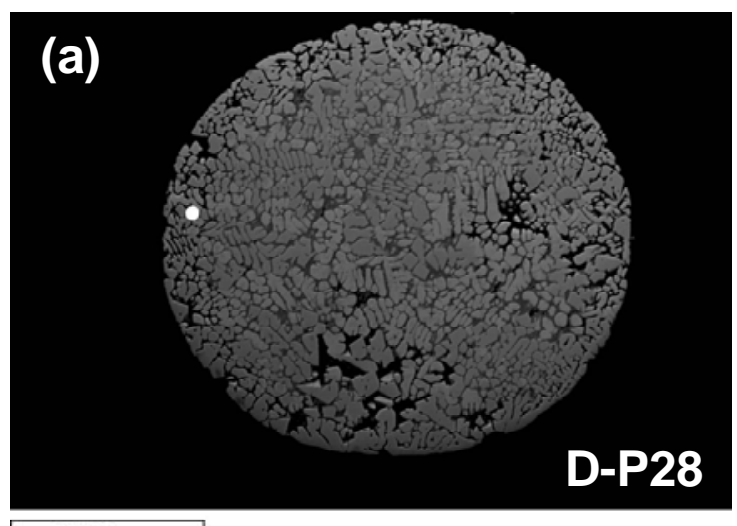

$100 \mu \mathrm{m}$
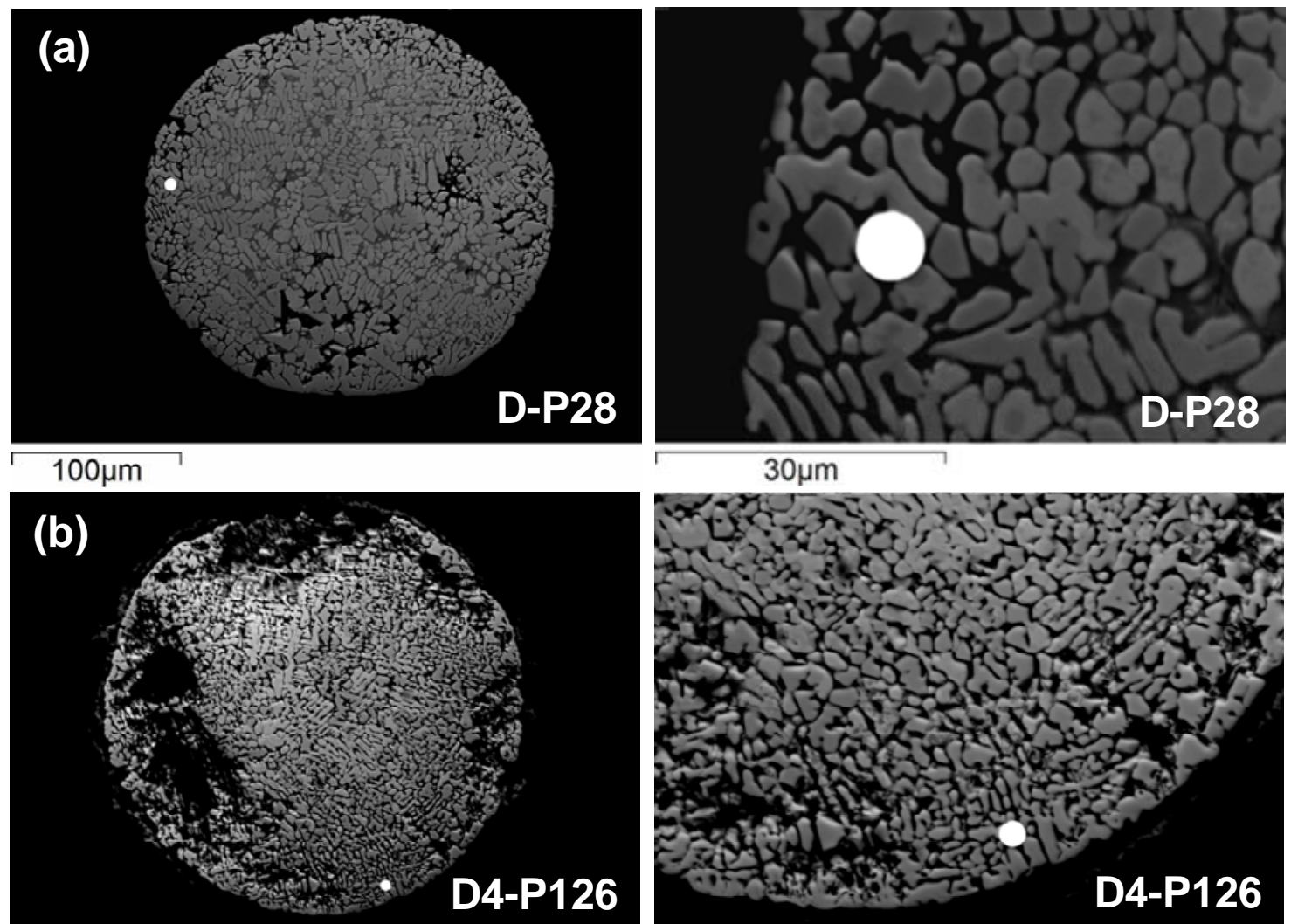

$30 \mu \mathrm{m}$

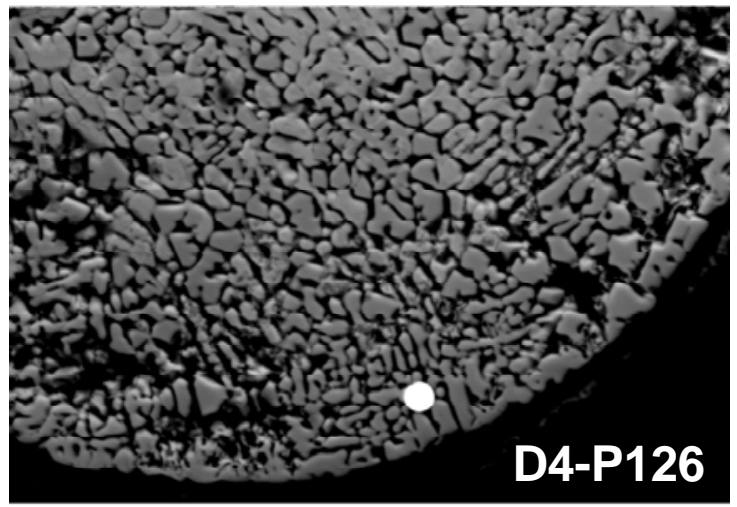

$100 \mu \mathrm{m}$

$50 \mu \mathrm{m}$

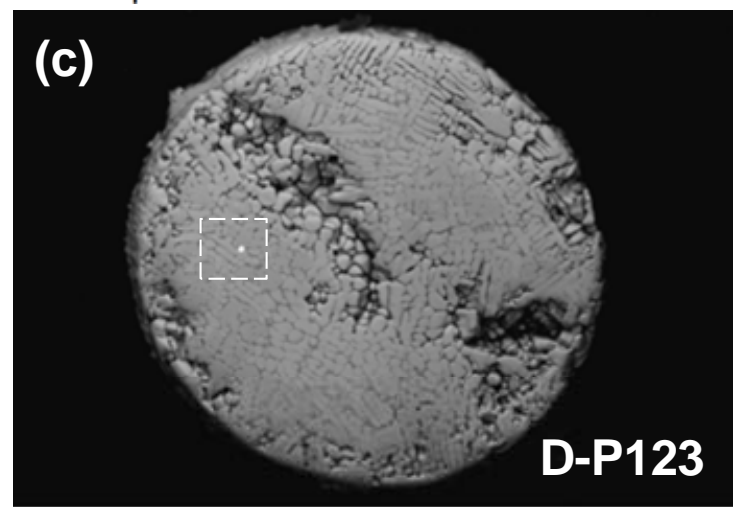

$100 \mu \mathrm{m}$

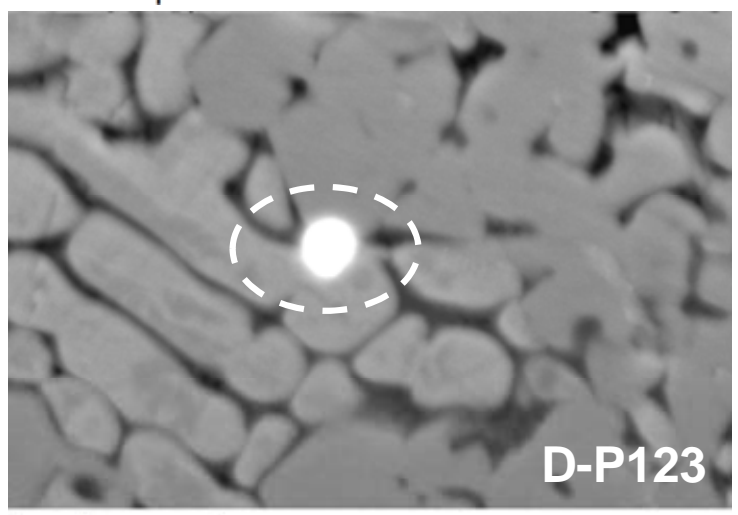

$10 \mu \mathrm{m}$ 
Fig. 4

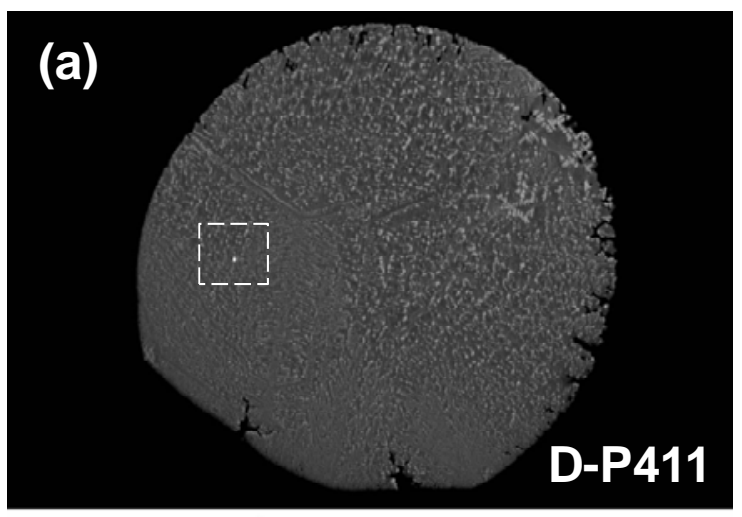

$100 \mu \mathrm{m}$
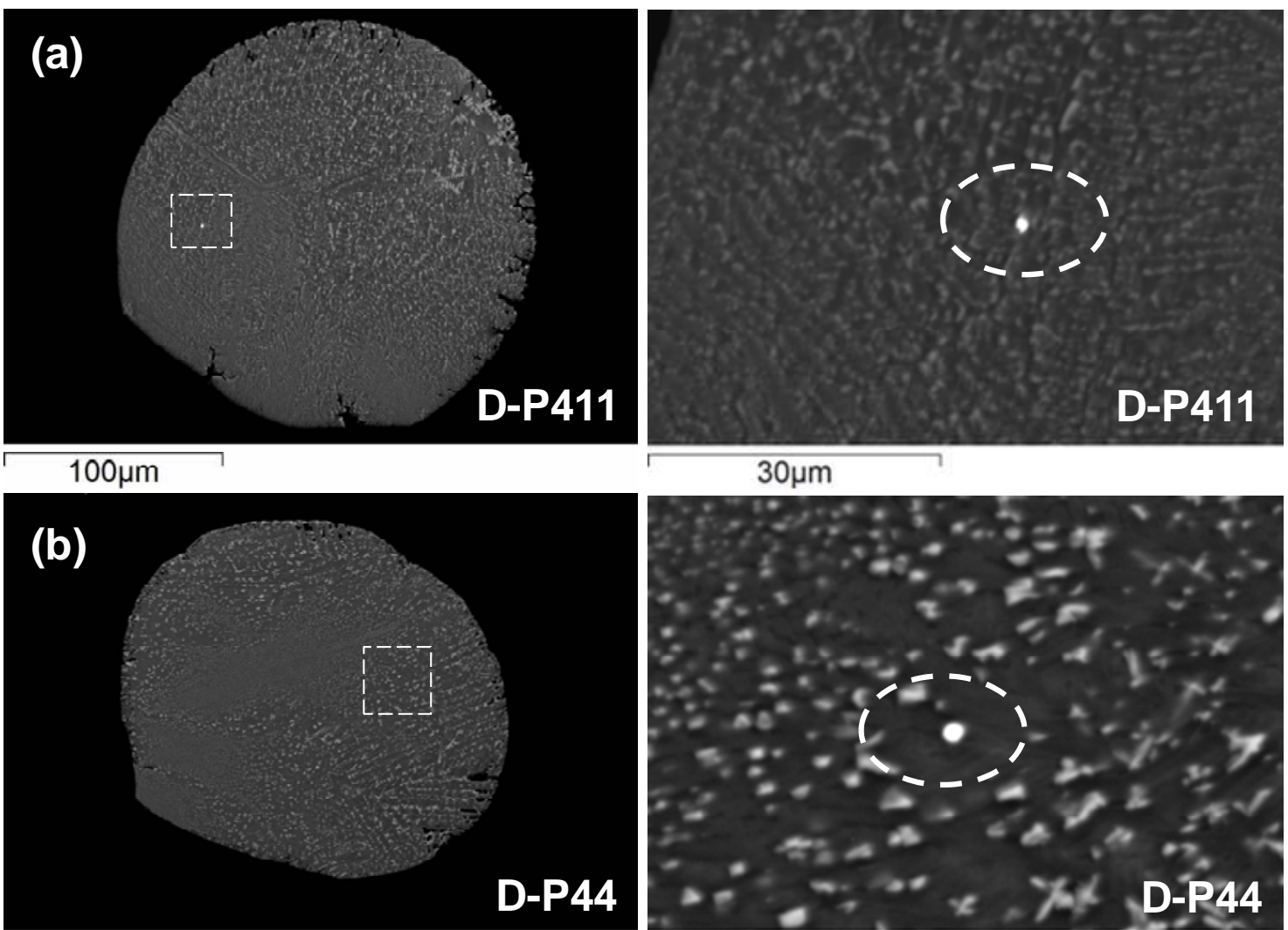

$100 \mu \mathrm{m}$

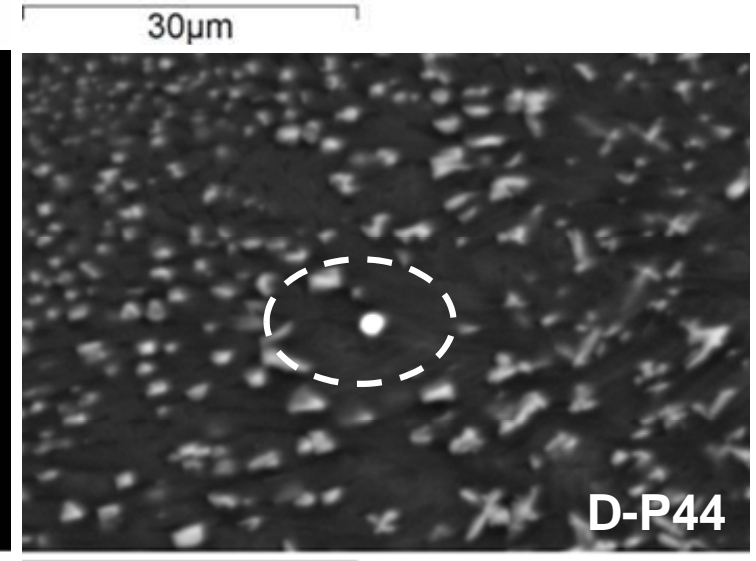

$20 \mu \mathrm{m}$

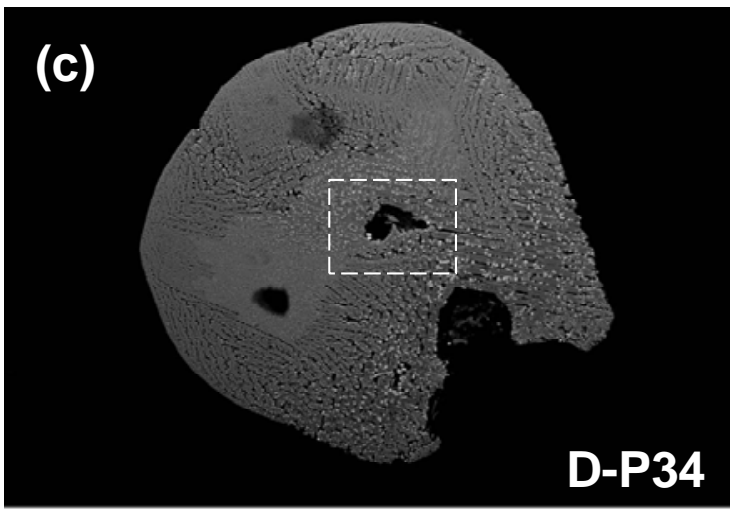

$200 \mu \mathrm{m}$

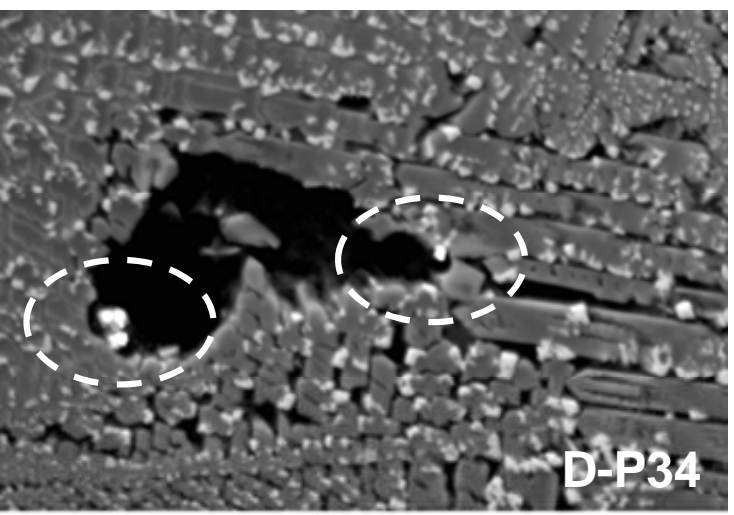

$30 \mu \mathrm{m}$ 
Fig. 5
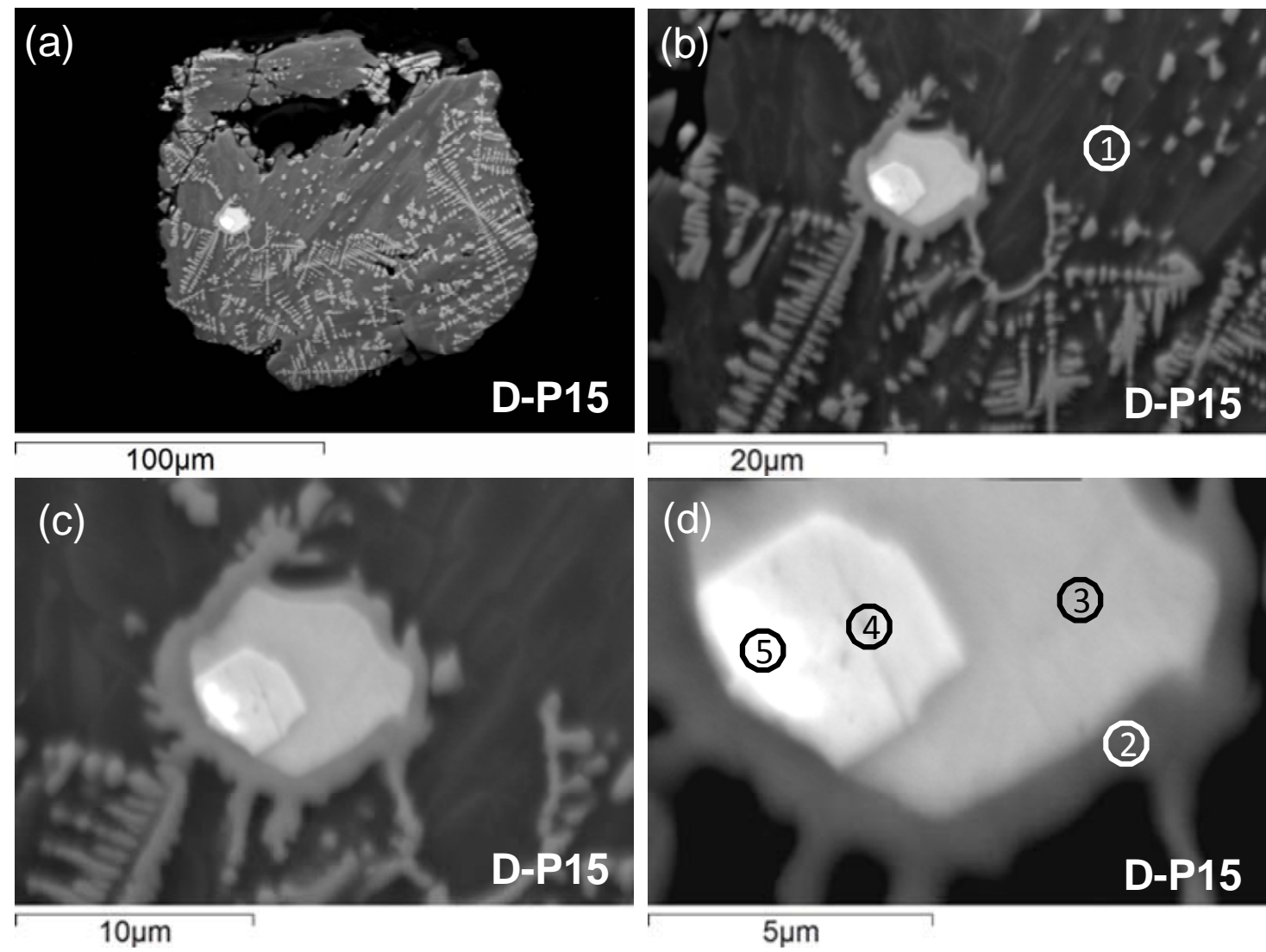

$20 \mu \mathrm{m}$

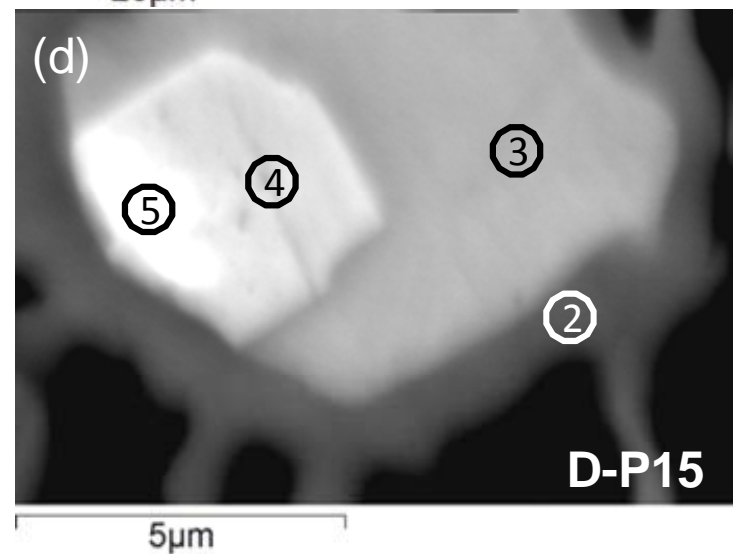


Fig. 6
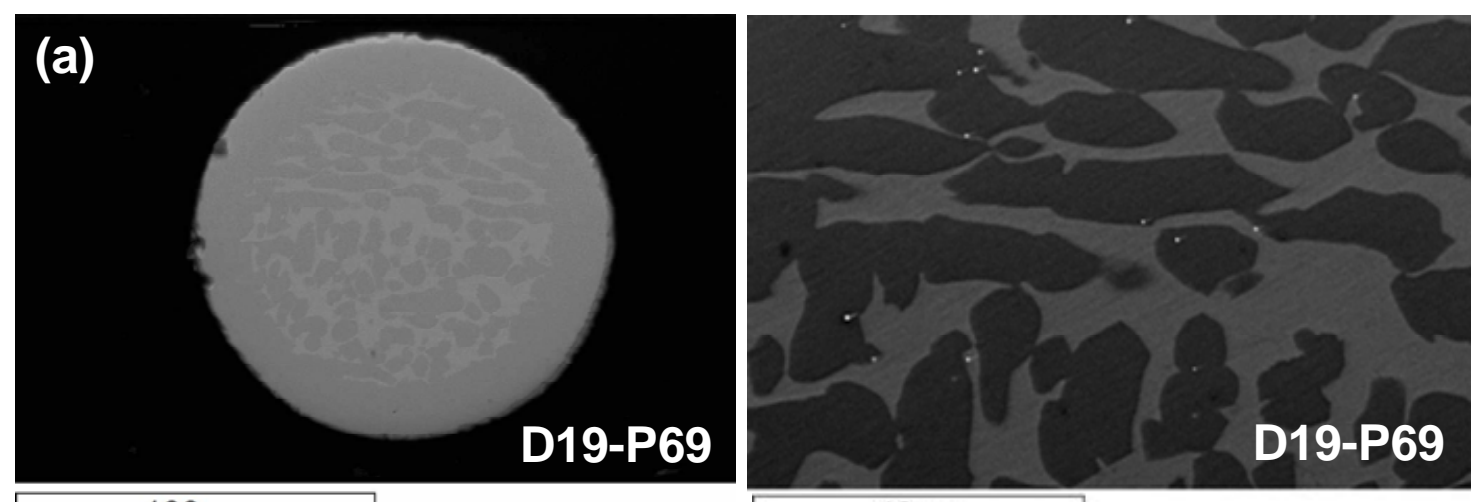

$100 \mu \mathrm{m}$

$40 \mu \mathrm{m}$
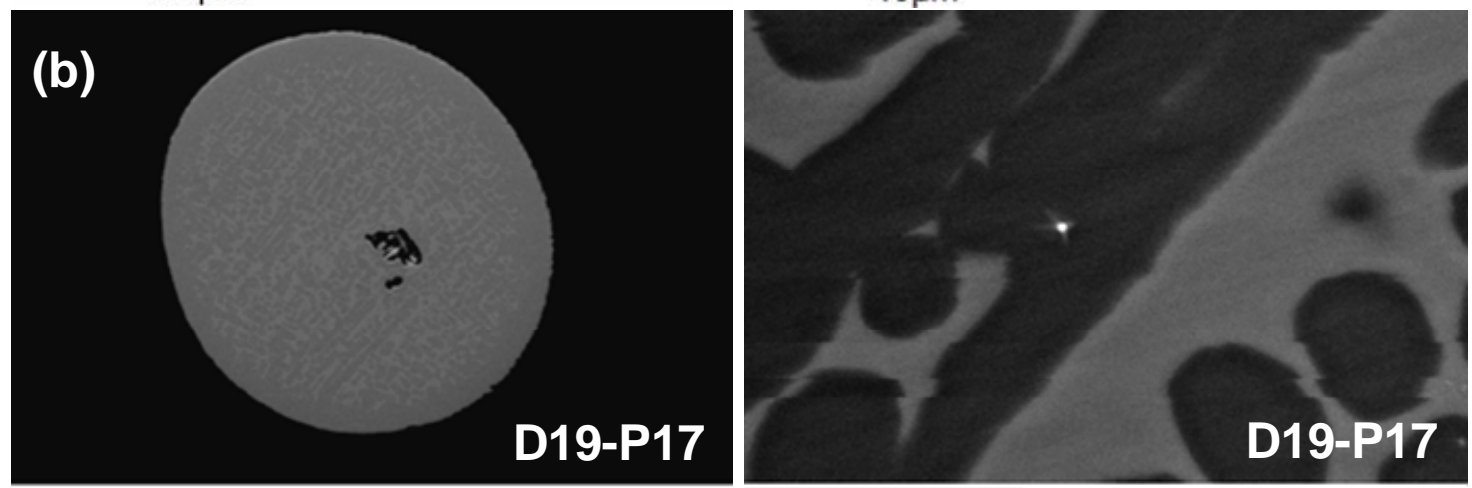

$200 \mu \mathrm{m}$

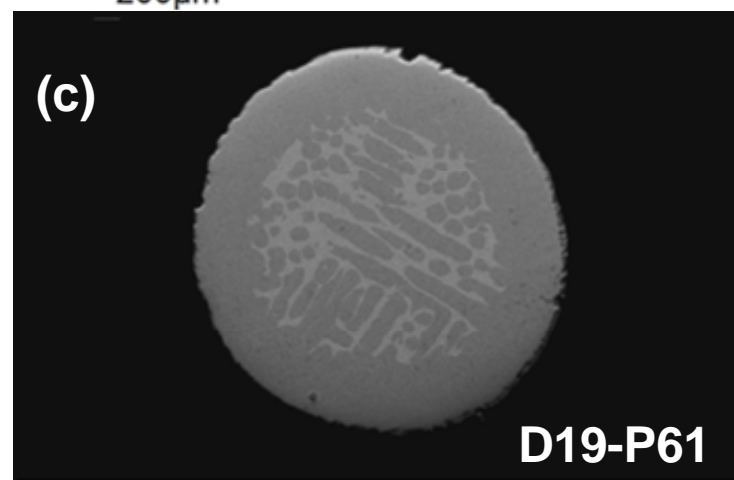

$100 \mu \mathrm{m}$

$10 \mu \mathrm{m}$

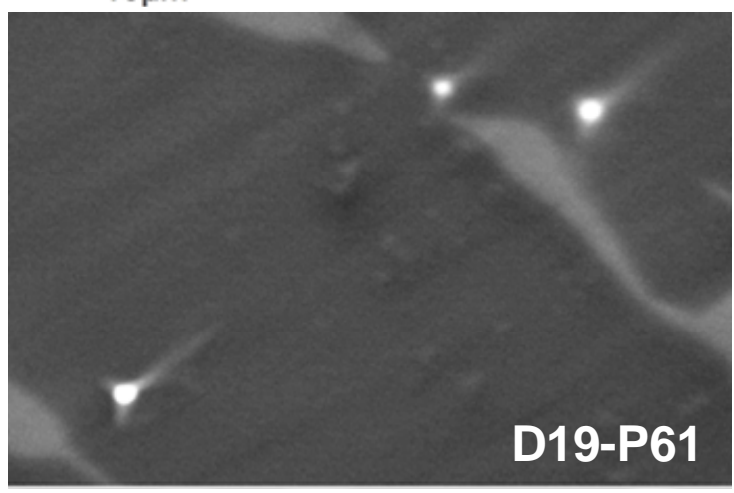

$5 \mu \mathrm{m}$ 
Fig. 7

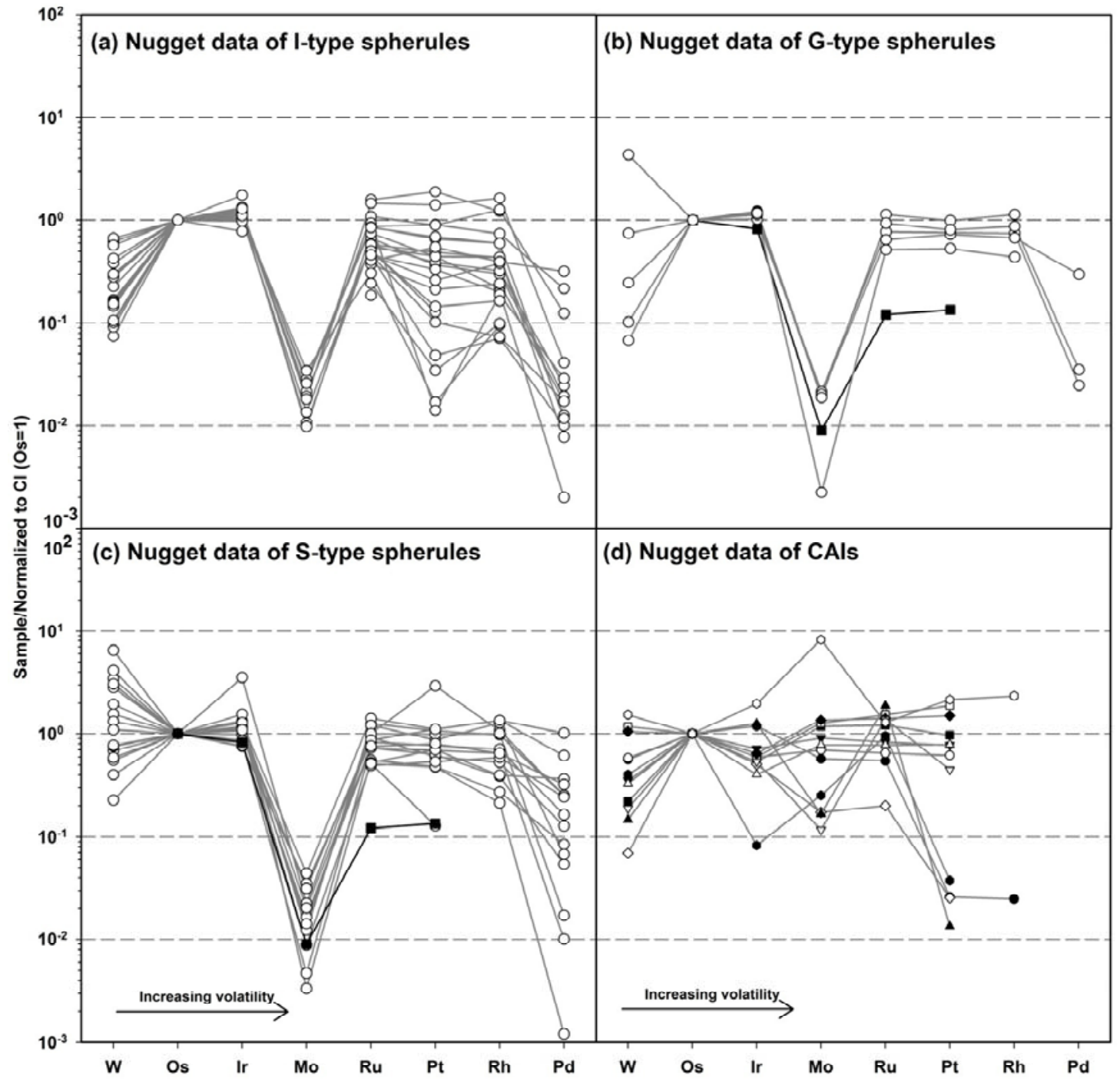


Fig. 8

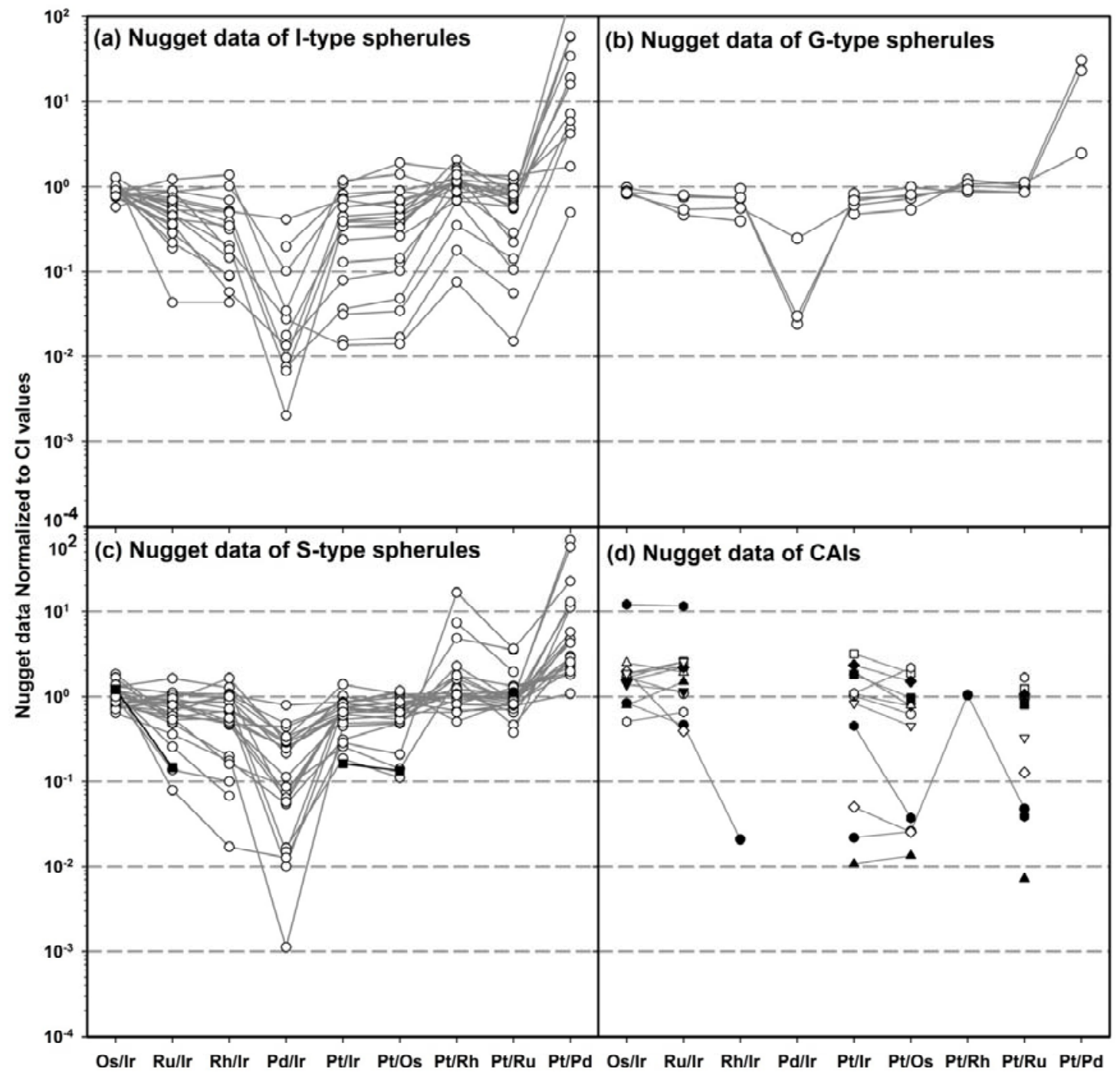


Fig. 9
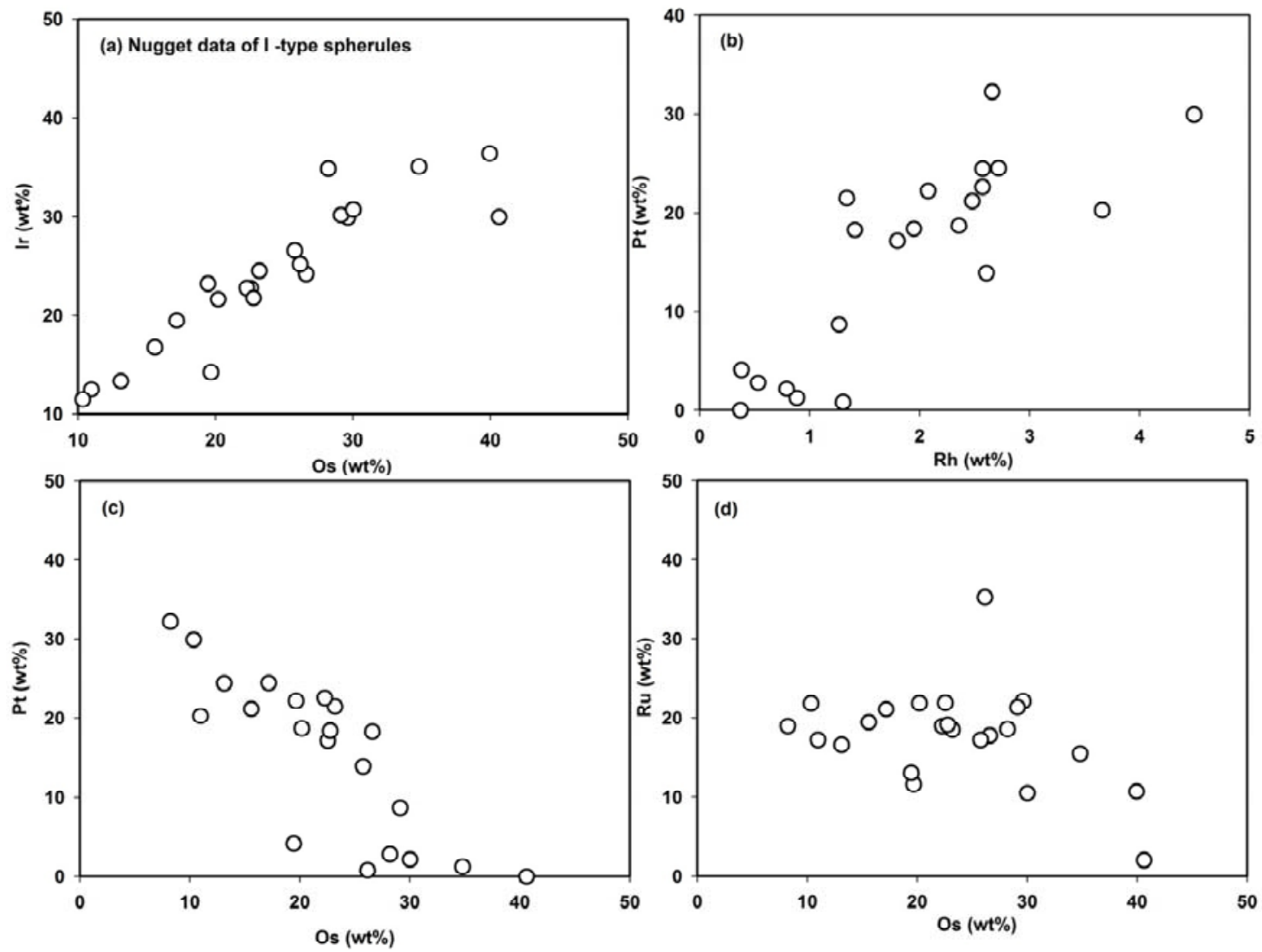
Fig. 10
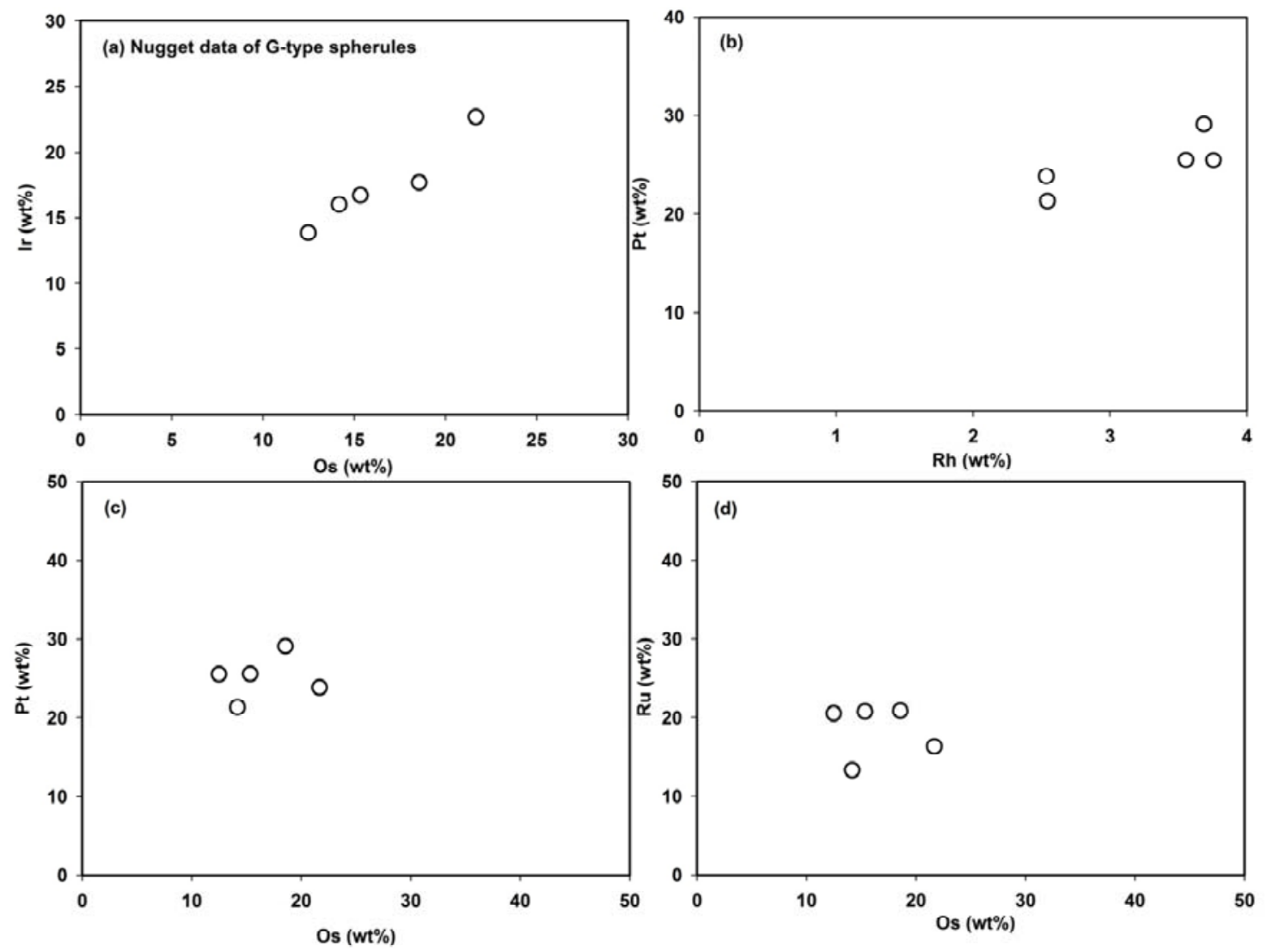
Fig. 11
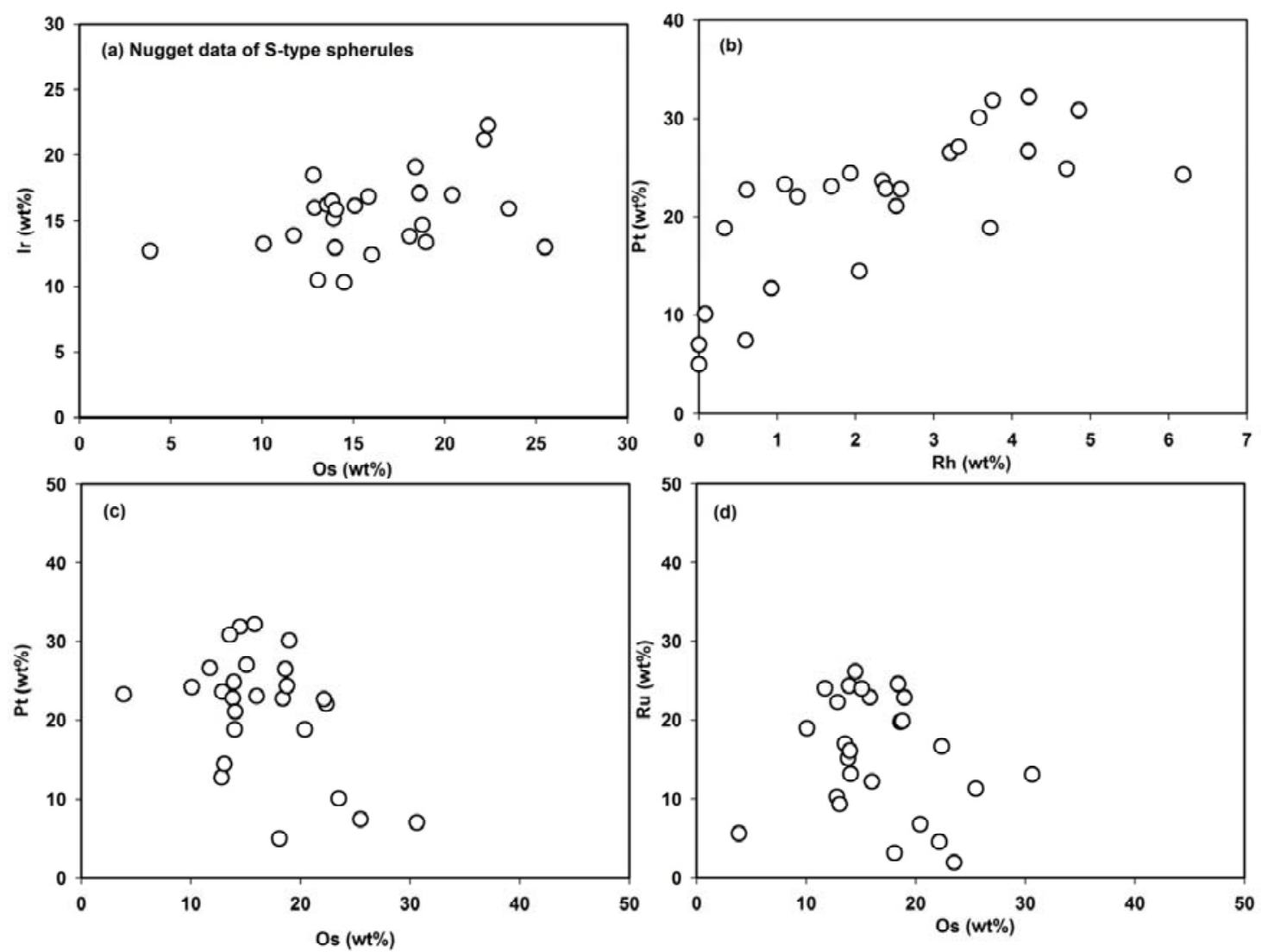
Fig. 12

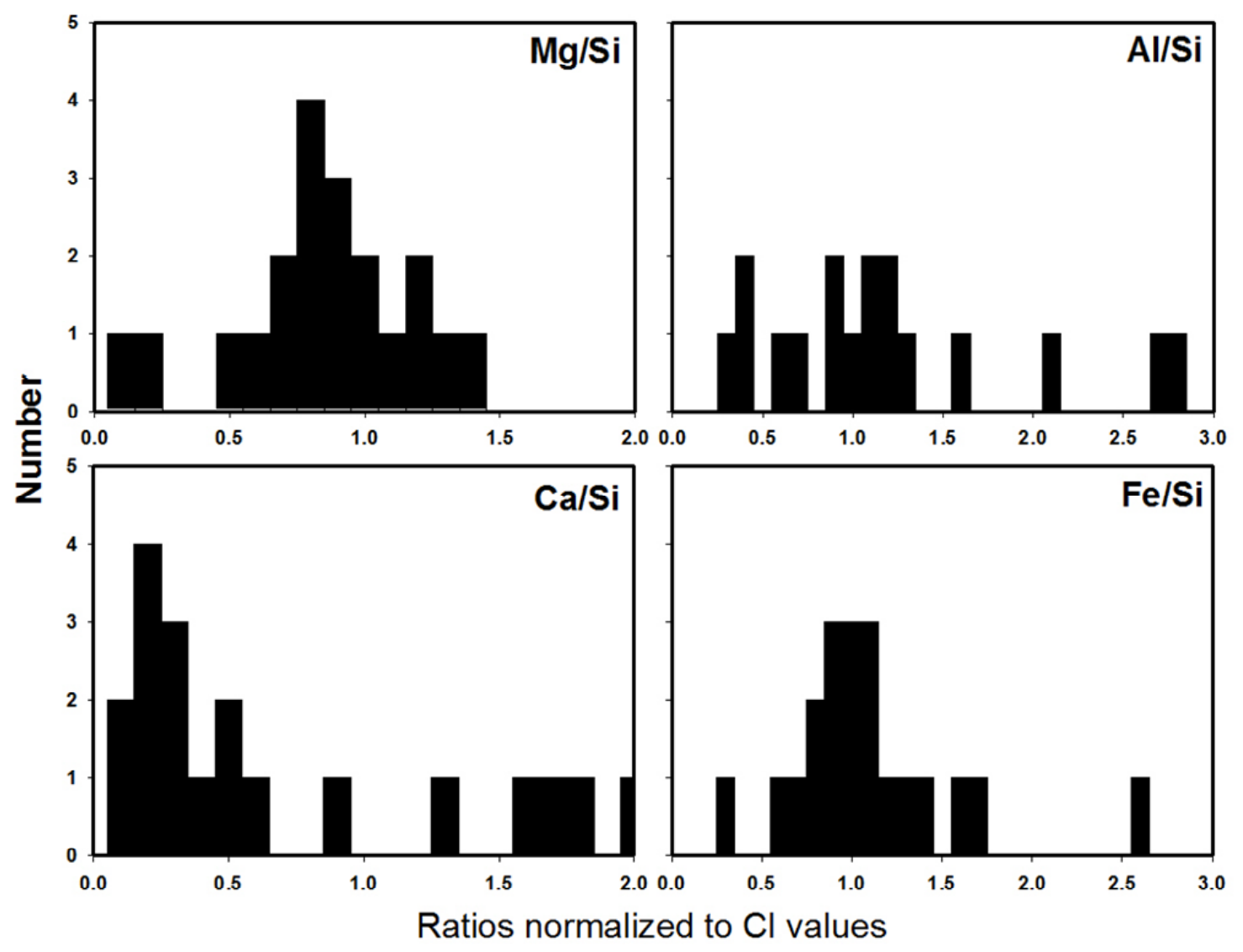


Fig. 13

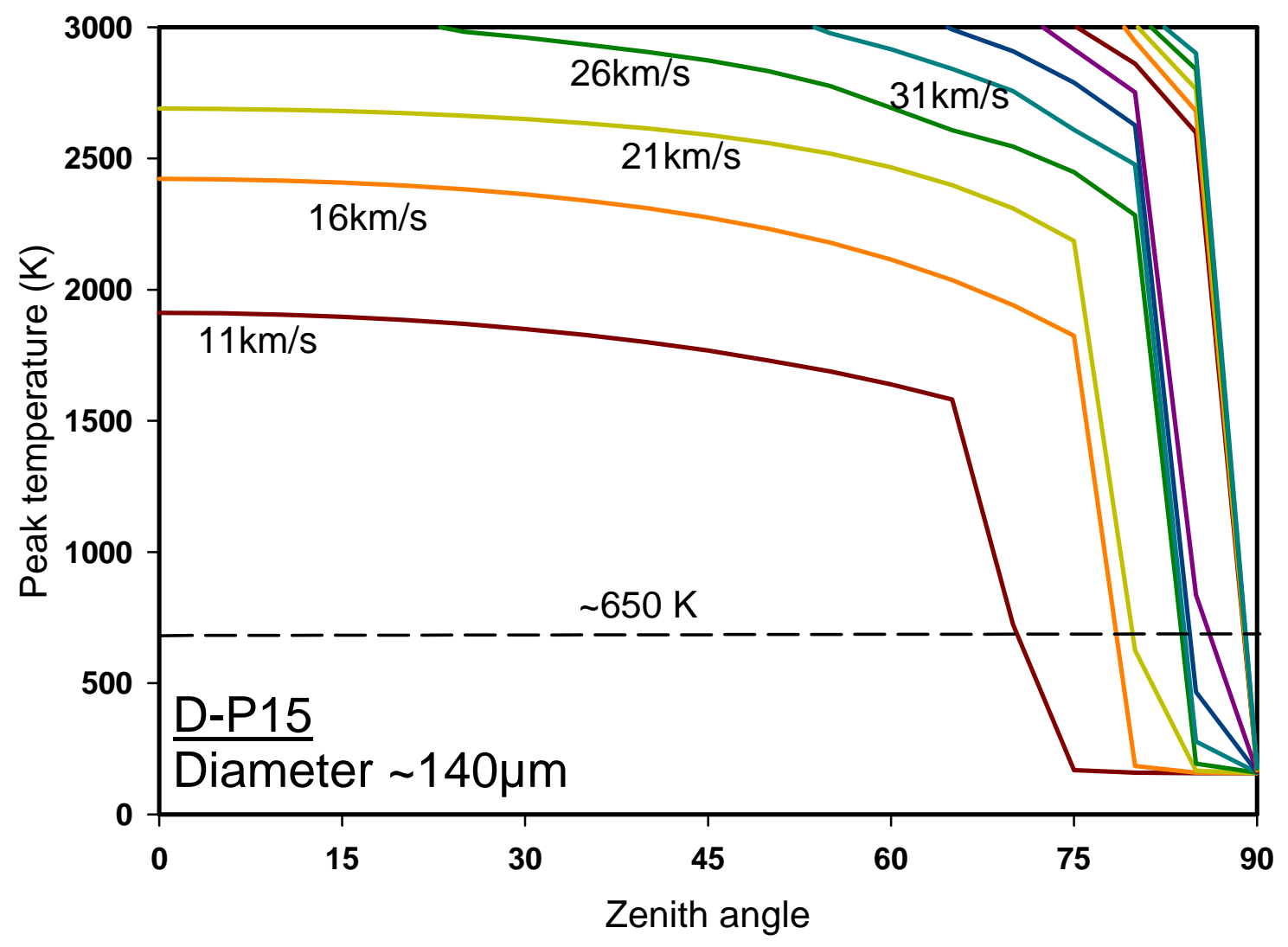




\section{Table 1}

Sample used to observe the presence of the RMNs in the spherules by polishing them at the depth level $\sim 5-10 \mu \mathrm{m}$.

\begin{tabular}{lrrrrr}
\hline \multicolumn{1}{c}{ Type } & Sub-type & $\begin{array}{r}\text { Spherules } \\
\text { observed }\end{array}$ & $\begin{array}{r}\text { Nugget } \\
\text { found in } \\
\text { spherules }\end{array}$ & $\begin{array}{r}\text { Total } \\
\text { number of } \\
\text { nugget }\end{array}$ & $\begin{array}{r}\text { Percent of } \\
\text { spherules with } \\
\text { nugget }\end{array}$ \\
\hline I-type & Barred & 511 & 23 & 23 & 7.9 \\
S-type & Porphyritic & 92 & 20 & 25 & 3.9 \\
& Scoracious & 11 & - & - & - \\
& Cryptocrystalline & 11 & - & - & - \\
& Glassy & 17 & - & - & - \\
G-type & Ca-rich & 1 & 1 & 1 & - \\
\hline Total & & 57 & 5 & 5 & 8.8 \\
\hline
\end{tabular}

* indicate Ca-rich spherule having nugget embedded in Fe-Ni and sulfide phase similar to fremdlinge found in CAIs. 
Table 2

The chemical composition of RMNs found in the cosmic spherules. The EDS data of the nugget are in $\mathrm{wt} \%$.

\begin{tabular}{|c|c|c|c|c|c|c|c|c|c|c|c|c|}
\hline ID & $\begin{array}{l}\text { Spherule } \\
\text { size } \mu \mathrm{m})\end{array}$ & $\begin{array}{l}\text { Nugget } \\
\text { size }(\mu \mathrm{m})\end{array}$ & $\mathrm{Fe}$ & $\mathrm{Ni}$ & Mo & $\mathrm{Ru}$ & $\mathrm{Rh}$ & $\mathrm{Pd}$ & W & Os & Ir & $\mathrm{Pt}$ \\
\hline \multicolumn{13}{|l|}{ I-type } \\
\hline D-P70 & 220 & 3.7 & 5.8 & 3.1 & - & 22.1 & - & - & 1.3 & 29.6 & 29.9 & 7.8 \\
\hline D-P14 & 295 & 4.9 & 7.6 & 3.8 & 0.9 & 18.5 & 1.3 & - & - & 23.2 & 24.5 & 21.5 \\
\hline D-P4 & 233 & 4.6 & 6.8 & 5.1 & - & 21.9 & 1.8 & 0.5 & 1.2 & 22.6 & 22.8 & 17.1 \\
\hline D-P14-I & 240 & 6.3 & 6.0 & 4.0 & - & 18.9 & 2.6 & 0.3 & - & 22.3 & 22.8 & 22.6 \\
\hline D-P374 & 225 & 4.4 & 9.1 & 2.2 & - & 18.5 & 0.5 & 0.3 & 3.3 & 28.2 & 34.8 & 2.8 \\
\hline D-P43 & 123 & 4.2 & 11.6 & 15.4 & 0.7 & 16.6 & 2.6 & 3.2 & - & 13.1 & 13.3 & 24.4 \\
\hline D-P214 & 192 & 4.5 & 8.1 & 6.0 & 0.6 & 19.1 & 1.9 & 0.6 & 0.6 & 22.8 & 21.8 & 18.4 \\
\hline \multirow[t]{2}{*}{ D-P218† } & 195 & 5.5 & 7.7 & 4.4 & - & 17.8 & 1.4 & 0.1 & 1.5 & 26.6 & 24.2 & 18.2 \\
\hline & & $2.5 \times 1$ & 68.3 & 3.5 & - & 5.0 & 0.6 & 0.2 & 1.2 & 9.1 & 8.6 & 4.0 \\
\hline D-P453 & 230 & 3.3 & 8.4 & 1.6 & 2.2 & 15.5 & 0.9 & - & - & 34.8 & 35.0 & 1.2 \\
\hline D-P456 & 236 & 5.7 & 7.3 & 6.9 & - & 21.9 & 2.4 & 0.2 & 1.5 & 20.2 & 21.6 & 18.7 \\
\hline D-P91 & 225 & 4.4 & 25.3 & 0.5 & - & 2.0 & 0.4 & - & 2.4 & 40.6 & 30.0 & - \\
\hline D-P125 & 252 & 7.8 & 5.9 & 20.0 & - & 18.9 & 2.7 & - & - & 8.2 & 13.4 & 32.2 \\
\hline D-P169 & 195 & 6.2 & 8.3 & 23.3 & - & 17.2 & 3.7 & 1.5 & 1.2 & 11.0 & 12.5 & 20.3 \\
\hline D-P190 & 186 & 4 & 10.6 & 0.8 & - & 35.3 & 1.3 & 0.8 & - & 26.2 & 25.1 & 0.8 \\
\hline D-P446 & 272 & 4.4 & 8.8 & 3.6 & - & 17.2 & 2.6 & - & 0.8 & 25.8 & 26.5 & 13.9 \\
\hline D3-P66 & 125 & 2.9 & 11.8 & 10.8 & - & 19.4 & 2.5 & - & 0.8 & 15.6 & 16.7 & 21.2 \\
\hline D2-P5 & 197 & 6.1 & 7.3 & 15.0 & - & 21.9 & 4.5 & 0.5 & - & 10.3 & 11.4 & 29.9 \\
\hline D2-P10 & 172 & 3.6 & 12.0 & 11.1 & - & 11.6 & 2.1 & 7.0 & 0.6 & 19.7 & 14.3 & 22.2 \\
\hline D2-P2 & 227 & 6.5 & 6.1 & 3.1 & - & 21.4 & 1.3 & - & 0.9 & 29.1 & 30.2 & 8.7 \\
\hline D2-P43 & 278 & 3.8 & 9.8 & 0.6 & - & 10.7 & - & - & 1.2 & 39.9 & 36.3 & - \\
\hline D2-P11 & 234 & 6.4 & 5.9 & 7.4 & 0.8 & 21.1 & 2.7 & 0.2 & - & 17.2 & 19.4 & 24.5 \\
\hline D-P13* & 192 & 3.3 & 20.2 & 2.9 & - & 10.5 & 0.8 & - & 1.7 & 30.0 & 30.7 & 2.1 \\
\hline D-P10* & 225 & 3.9 & 33.4 & 3.6 & - & 13.1 & 0.4 & 0.4 & 1.6 & 19.5 & 23.2 & 4.1 \\
\hline \multicolumn{13}{|l|}{ G-type } \\
\hline D-P28 & 327 & 7.2 & 5.0 & 3.9 & 0.7 & 20.9 & 3.7 & 0.5 & 0.4 & 18.6 & 17.7 & 29.1 \\
\hline D-P14-II & 140 & 3.1 & 10.1 & 1.3 & - & 16.3 & 2.5 & - & 1.0 & 21.7 & 22.7 & 23.8 \\
\hline D-P365 & 240 & 1.5 & 14.4 & 1.0 & 0.5 & 13.3 & 2.5 & 4.8 & 11.7 & 14.2 & 16.0 & 21.3 \\
\hline D-P123 & 255 & 2.6 & 12.8 & 9.1 & - & 20.5 & 3.8 & - & 1.8 & 12.5 & 13.9 & 25.5 \\
\hline D4-P126 & 240 & 5.1 & 8.1 & 9.9 & 0.5 & 20.8 & 3.6 & 0.6 & 0.2 & 15.3 & 16.7 & 25.5 \\
\hline \multicolumn{13}{|l|}{ S-type } \\
\hline D-P6 & 240 & 0.9 & 12.5 & 0.9 & 0.3 & 22.3 & 2.3 & 1.4 & 7.4 & 12.9 & 16.0 & 23.7 \\
\hline D-P44 & 225 & 1 & 8.1 & - & 0.6 & 19.8 & 3.2 & 0.2 & 5.5 & 18.6 & 17.1 & 26.5 \\
\hline D-P88 & 230 & 1.1 & 9.9 & 0.1 & 0.4 & 16.7 & 1.3 & - & 5.6 & 22.4 & 22.3 & 22.1 \\
\hline D-P17 & 350 & 2.3 & 5.9 & 0.5 & 1.2 & 22.9 & 3.6 & 3.5 & 1.4 & 19.0 & 13.3 & 30.1 \\
\hline & & & & & & & & & & & & \\
\hline
\end{tabular}




\begin{tabular}{|c|c|c|c|c|c|c|c|c|c|c|c|c|}
\hline D-P100 & 408 & 2.1 & 4.5 & 0.7 & 1.1 & 24.6 & 2.6 & 2.6 & 1.9 & 18.4 & 19.1 & 22.8 \\
\hline \multirow[t]{2}{*}{ D-P55 } & 265 & 1.7 & 5.4 & 0.6 & - & 26.2 & 3.8 & 4.1 & 1.9 & 14.5 & 10.3 & 31.9 \\
\hline & & 1.6 & 13.2 & 0.7 & 0.2 & 19.8 & 1.9 & 1.1 & 6.9 & 18.8 & 14.7 & 24.4 \\
\hline \multirow[t]{4}{*}{ D-P34 } & 306 & 1.4 & 10.8 & 22.8 & 0.1 & 10.3 & 0.9 & 1.2 & 8.3 & 12.8 & 18.5 & 12.8 \\
\hline & & 1.3 & 10.1 & 37.1 & 0.2 & 5.6 & 1.1 & 1.1 & 4.7 & 3.9 & 12.7 & 23.3 \\
\hline & & 1.2 & 9.3 & 26.7 & - & 11.3 & 0.6 & 1.4 & 4.5 & 25.5 & 13.0 & 7.4 \\
\hline & & 1.3 & 7.4 & 19.2 & 0.4 & 13.1 & - & 0.3 & 3.4 & 30.6 & 17.0 & 7.0 \\
\hline D-P80 & 265 & 0.6 & 18.7 & 0.1 & - & 6.8 & 0.3 & - & 17.7 & 20.4 & 17.0 & 18.8 \\
\hline D-P98 & 327 & 2.5 & 2.6 & - & 1.0 & 24.1 & 4.2 & 13.3 & 1.7 & 11.7 & 13.9 & 26.7 \\
\hline D-P3 & 245 & 0.5 & 16.0 & 0.2 & - & 4.6 & 0.6 & - & 12.8 & 22.1 & 21.2 & 22.7 \\
\hline D1-P4 & 220 & 1.8 & 14.5 & 0.8 & - & 24.4 & 4.7 & 1.1 & 2.0 & 13.9 & 15.2 & 24.9 \\
\hline D-P9 & 180 & 2.3 & 3.9 & 0.1 & 0.4 & 22.9 & 4.2 & 0.3 & 1.8 & 15.8 & 16.9 & 32.2 \\
\hline D-P411 & 220 & 1.4 & 17.4 & 1.8 & - & 12.2 & 1.7 & 6.6 & 8.6 & 16.0 & 12.4 & 23.1 \\
\hline D-P325 & 170 & 1.2 & 38.1 & 1.3 & - & 9.3 & 2.0 & 3.6 & 7.6 & 13.1 & 10.5 & 14.5 \\
\hline D-P312 & 245 & 1.3 & 29.3 & 6.4 & - & 2.0 & 0.1 & 0.2 & 10.8 & 23.5 & 15.9 & 10.1 \\
\hline D-P254 & 240 & 2.5 & 6.7 & 0.6 & - & 17.0 & 4.9 & 9.3 & 2.8 & 13.6 & 16.2 & 30.9 \\
\hline \multirow[t]{2}{*}{ D-P287 } & 295 & 0.9 & 13.2 & 1.2 & 0.5 & 15.2 & 2.4 & 5.0 & 10.8 & 13.8 & 16.5 & 22.9 \\
\hline & & 0.7 & 14.3 & 1.0 & 0.5 & 13.2 & 2.5 & 4.7 & 11.6 & 14.0 & 15.9 & 21.1 \\
\hline D-P64 & 275 & 2.8 & 19.9 & 0.5 & 0.2 & 19.0 & 6.2 & 4.6 & 2.4 & 10.1 & 13.2 & 24.3 \\
\hline D-P56 & 248 & 1.9 & 5.9 & 0.8 & - & 24.1 & 3.3 & 5.8 & 1.1 & 15.1 & 16.1 & 27.1 \\
\hline D-P1 & 235 & 2.1 & 20.5 & 1.4 & - & 16.1 & 3.7 & 5.2 & 7.0 & 14.0 & 12.9 & 18.9 \\
\hline D-P15** & 175 & $1.4 \times 0.6$ & 6.7 & 54.8 & 0.3 & 3.2 & - & - & - & 18.1 & 13.8 & 5.0 \\
\hline
\end{tabular}

$\dagger$ indicates spherule has a small elongated shaped nugget attached to large nugget.

* indicates whole spherule observed in SEM having presence of nugget on the surface.

** indicates the Ca-rich spherule having nugget similar to fremdlinge found in CAIs. 
Table 3

The chemical composition of nanometer sized nugget from I-type spherules. The EDS data of the nugget are in $w t \%$.

\begin{tabular}{|c|c|c|c|c|c|c|c|c|c|}
\hline Spherule & $\#$ & $\mathrm{Fe}$ & $\mathrm{Ni}$ & $\mathrm{Ru}$ & $\mathrm{Rh}$ & $\mathrm{Pd}$ & Os & $\mathrm{Ir}$ & $\mathrm{Pt}$ \\
\hline \multirow[t]{6}{*}{ D19-P27 } & 1 & 83.4 & 1.6 & 0.2 & 0.9 & 0.3 & - & - & 13.6 \\
\hline & 2 & 79.7 & 2.2 & - & 1.0 & - & 0.4 & - & 16.5 \\
\hline & 3 & 79.7 & 2.2 & - & 1.0 & - & 0.4 & - & 16.5 \\
\hline & 4 & 78.4 & 2.3 & 0.4 & 1.3 & - & - & - & 17.7 \\
\hline & 5 & 88.8 & 3.3 & - & 0.5 & - & - & - & 7.4 \\
\hline & 6 & 88.8 & 1.4 & 0.2 & 0.8 & - & - & - & 8.6 \\
\hline \multirow[t]{5}{*}{ D19-P61 } & 1 & 94.6 & 0.2 & - & - & - & - & 0.1 & 5.1 \\
\hline & 2 & 94.6 & & 0.2 & 0.2 & - & - & - & 5.0 \\
\hline & 3 & 95.9 & 0.1 & - & - & 0.1 & - & - & 3.9 \\
\hline & 4 & 96.3 & 0.1 & 0.2 & 0.2 & 0.1 & - & - & 3.2 \\
\hline & 5 & 98.0 & 0.1 & 0.1 & - & - & - & 0.2 & 1.6 \\
\hline \multirow[t]{5}{*}{ D19-P65 } & 1 & 74.1 & 12.4 & 0.1 & 1.4 & - & - & - & 11.9 \\
\hline & 2 & 76.5 & 12.7 & 0.1 & 1.4 & - & - & - & 9.4 \\
\hline & 3 & 86.3 & 9.6 & 0.1 & 0.5 & - & - & - & 3.4 \\
\hline & 4 & 85.1 & 10.6 & - & 0.6 & 0.1 & - & - & 3.7 \\
\hline & 5 & 87.7 & 9.9 & - & 0.6 & - & - & - & 1.8 \\
\hline \multirow[t]{5}{*}{ D19-P69 } & 1 & 73.3 & 4.1 & 0.4 & 1.6 & 0.4 & 0.2 & - & 20.0 \\
\hline & 2 & 68.1 & 2.7 & 0.1 & 1.9 & - & 0.4 & - & 26.7 \\
\hline & 3 & 85.9 & 4.0 & - & 0.8 & - & 0.1 & - & 9.2 \\
\hline & 4 & 80.9 & 2.8 & 0.4 & 1.2 & 0.3 & - & - & 14.4 \\
\hline & 5 & 87.4 & 1.9 & 0.1 & 0.5 & - & 0.4 & - & 9.7 \\
\hline \multirow[t]{3}{*}{ D19-P87 } & 1 & 92.6 & 5.9 & - & - & 0.2 & - & 0.2 & 1.0 \\
\hline & 2 & 83.8 & 9.8 & 0.1 & 0.4 & - & - & - & 5.9 \\
\hline & 3 & 90.2 & 6.1 & 0.3 & 0.2 & 0.1 & - & - & 3.2 \\
\hline \multirow[t]{4}{*}{ D19-P17 } & 1 & 95.4 & 2.4 & - & - & - & - & 0.1 & 2.1 \\
\hline & 2 & 97.4 & 1.3 & 0.3 & 0.2 & - & - & 0.5 & 0.4 \\
\hline & 3 & 95.2 & 1.3 & - & 0.1 & - & 0.2 & - & 3.2 \\
\hline & 4 & 82.8 & 2.9 & 0.2 & 0.8 & - & - & - & 13.2 \\
\hline \multirow[t]{4}{*}{ D19-P12 } & 1 & 86.2 & 3.7 & 0.3 & 0.5 & - & - & - & 9.4 \\
\hline & 2 & 83.5 & 4.5 & - & 0.6 & 0.2 & - & - & 11.1 \\
\hline & 3 & 90.1 & 3.7 & - & 0.5 & - & - & - & 5.7 \\
\hline & 4 & 85.9 & 6.3 & 0.2 & 0.8 & - & - & - & 6.9 \\
\hline
\end{tabular}




\section{Table 4}

a) Chemical composition (wt\%) of the marked region 1 and 2 (Fig. 4 ) in cosmic spherule D-P15.

\begin{tabular}{lrr}
\hline Element point & \multicolumn{1}{c}{1} & \multicolumn{1}{c}{2} \\
\hline $\mathrm{MgO}$ & 15.8 & 13.5 \\
$\mathrm{Al}_{2} \mathrm{O}_{3}$ & 2.2 & 2.3 \\
$\mathrm{SiO}_{2}$ & 32.1 & 8.3 \\
$\mathrm{SO}_{3}$ & & 1.9 \\
$\mathrm{CaO}$ & 16.8 & 4.4 \\
$\mathrm{Cr}_{2} \mathrm{O}_{3}$ & 0.5 & 0.5 \\
$\mathrm{MnO}$ & 0.4 & \\
$\mathrm{FeO}$ & 30.7 & 46.3 \\
$\mathrm{NiO}$ & 1.2 & 22.3 \\
\hline
\end{tabular}

b) Elemental composition (wt\%) of the sulfide and the Fe-Ni (marked as 3 and 4, respectively in Fig. 4) composition surrounding the nugget.

\begin{tabular}{lrr}
\hline Element|point & \multicolumn{1}{c}{3} & 4 \\
\hline $\mathrm{S}$ & 26.0 & \\
$\mathrm{Fe}$ & 3.8 & 7.9 \\
$\mathrm{Ni}$ & 69.9 & 91.7 \\
\hline
\end{tabular}

